\title{
Mitochondrial Proteolysis and Metabolic Control
}

\author{
Sofia Ahola, Thomas Langer, and Thomas MacVicar \\ Department of Mitochondrial Proteostasis, Max Planck Institute for Biology of Ageing, 50931 Cologne, Germany \\ Correspondence: tmacvicar@age.mpg.de
}

\begin{abstract}
Mitochondria are metabolic hubs that use multiple proteases to maintain proteostasis and to preserve their overall quality. A decline of mitochondrial proteolysis promotes cellular stress and may contribute to the aging process. Mitochondrial proteases have also emerged as tightly regulated enzymes required to support the remarkable mitochondrial plasticity necessary for metabolic adaptation in a number of physiological scenarios. Indeed, the mutation and dysfunction of several mitochondrial proteases can cause specific human diseases with severe metabolic phenotypes. Here, we present an overview of the proteolytic regulation of key mitochondrial functions such as respiration, lipid biosynthesis, and mitochondrial dynamics, all of which are required for metabolic control. We also pay attention to how mitochondrial proteases are acutely regulated in response to cellular stressors or changes in growth conditions, a greater understanding of which may one day uncover their therapeutic potential.
\end{abstract}

$M$ ore than a billion years of evolution since their fateful endosymbiotic origin have directed mitochondria to play central roles in metabolism and other cellular functions. For instance, precise regulation of mitochondrial function is required for the production of ATP by oxidative phosphorylation (OXPHOS), the maintenance of calcium homeostasis, and programmed cell death. Only 13 mitochondrial proteins ( $\sim 1 \%$ of the total mitochondrial proteome) are encoded by resident mitochondrial DNA (mtDNA) with the remainder originating from the nucleus. These proteins are synthesized on cytosolic ribosomes and directed to four distinct submitochondrial compartments that are defined by the organelle's unique double membrane-bound structure. The mitochondrial matrix is surrounded by the cristae-forming inner mitochondrial membrane (IMM), which is separated from the cytosol by the intermembrane space (IMS) and outer mitochondrial membrane (OMM). Proteostasis in each subcompartment is maintained by a number of mitochondrial proteases (mitoproteases) that promote protein quality control by degrading misfolded proteins and by processing newly imported proteins to facilitate their biogenesis (Quiros et al. 2015). Mitochondrial proteolysis is therefore a frontline mitochondrial qualitycontrol mechanism that combines with others, including reactive oxygen species (ROS) scavenging and mitophagy, to maintain overall mitochondrial fitness.

Acting as quality-control enzymes, all mitoproteases are likely to impact metabolism because mitochondria represent a core metabolic

Editors: Richard I. Morimoto, F. Ulrich Hartl, and Jeffery W. Kelly

Additional Perspectives on Protein Homeostasis available at www.cshperspectives.org

Copyright (C) 2019 Cold Spring Harbor Laboratory Press; all rights reserved; doi: 10.1101/cshperspect.a033936

Cite this article as Cold Spring Harb Perspect Biol 2019;11:a033936 
S. Ahola et al.

hub. Nevertheless, recent advancements have demanded that we look beyond this classical description of mitoproteases. It is now clear that mitochondrial proteolysis offers a valuable node for the regulation of specific mitochondrial functions and can be modulated by an array of signaling inputs. Consequently, dysfunctional mitoproteases contribute to a plethora of human diseases, including cancer and neurodegeneration and are strongly associated with the aging process. The loss of mitoprotease function in these diseases impairs mitochondrial function and causes metabolic-associated phenotypes. In this review, we will focus on the close and often reciprocal relationship between mitoproteases and metabolic control. We will highlight the impact of mitoproteases on pathogenesis and health span, a greater understanding of which may one day propel these enzymes forward as therapeutic targets.

\section{PROTEOLYSIS ORGANIZES THE MITOCHONDRIAL PROTEOME}

Mitochondria contain at least 20 intrinsic and catalytically functional proteases, which are divided into three catalytic classes: 12 metalloproteases, seven Ser proteases, and one Cys protease (Quiros et al. 2015). The intrinsic mitoproteases are distributed between the submitochondrial compartments in which they contribute to mitochondrial function and homeostasis by cleaving or completely degrading target substrates. A common feature of mitoproteases is their pleiotropic nature, which arises from the fact that a protease may have multiple diverse substrates. The best examples of multisubstrate mitoproteases are those that regulate mitochondrial protein import and biogenesis.

Newly synthesised mitochondrial proteins must be imported and sorted to the correct mitochondrial subcompartment. The majority of these proteins contain an amino-terminal targeting signal, or presequence, which can be cleaved by a number of processing peptidases located in the matrix or IMM. Arguably the most common example is the essential and conserved mitochondrial-processing peptidase (MPP) complex, which is a heterodimer com- prised of the peptidase PMCB and its noncatalytic homolog PMCA (Mossmann et al. 2012). A matrix soluble complex, MPP processes the positively charged presequence of the vast majority of newly imported proteins destined for the matrix, IMM or IMS. Discarded presequence peptides are targeted by proteases within mitochondria, such as Cym1 and Ste23 in yeast or PreP in humans, to be rapidly degraded and to prevent their potentially toxic accumulation (Stahl et al. 2002; Kambacheld et al. 2005; Falkevall et al. 2006; Mossmann et al. 2014; Taskin et al. 2017).

Mitoproteases mediating the processing of newly imported proteins often affect the subsequent sorting of those proteins within mitochondria. For example, the inner mitochondrial membrane peptidases (IMMPs) release soluble proteins into the IMS by cleaving off their hydrophobic sorting signals. The regulation of protein import and sorting by proteolysis therefore has a huge impact on mitochondrial metabolism, for instance by ensuring the assembly of OXPHOS complexes to drive the generation of ATP. Consequently, mutations in MPPs cause a number of diseases in humans, with neurodegenerative disorders being the most prevalent. Mutation of either MPP subunit gene, PMPCA or $P M P C B$, causes similar early-onset neurological phenotypes in patients, with the cerebellum being particularly affected (Jobling et al. 2015; Choquet et al. 2016; Joshi et al. 2016; Vogtle et al. 2018). Mutations within PMPCB appear to produce more severe symptoms, perhaps because mutation of the catalytic subunit disturbs MPP processing activity to the greater extent (Vogtle et al. 2018). Furthermore, and to highlight the range of diseases caused by processing peptidase defects, mutation of IMMP subunit 2-like protease (IMMP2) is associated with developmental disorders such as Tourette syndrome, whereas mutation of MIPEP, encoding the mitochondrial intermediate peptidase (MIP/Oct1), causes infant heart failure (Petek et al. 2001; Bertelsen et al. 2014; Eldomery et al. 2016). Specific diseases associated with mitochondrial dysfunction (broadly termed as mitochondriopathies) are also triggered by mutations in the presequences of mitochondrial proteins. For exam- 
ple, impaired MPP processing of mutant Frataxin leads to disturbed iron homeostasis and the neurodegenerative disorder Friedreich's ataxia (Gakh et al. 2002), and a homozygous mutation at the MPP-processing site of the protease YME1L was recently found to impair maturation and destabilize the protein resulting in neuropathy and optic atrophy (Hartmann et al. 2016).

Proteases can also modulate mitochondrial protein import by regulating components of the import machinery. For instance, carboxy-terminal processing of the transmembrane protein Mgr2 by Imp (yeast IMMP) is required for proper assembly and stabilization of the translocase of inner mitochondrial membrane 23 (Tim23/TIMM23) complex (Ieva et al. 2013). Curiously, in comparison to yeast and fungal Mgr2, the mammalian homolog ROMO1, which has been attributed to diverse mitochondrial functions besides protein import, lacks an IMMP cleavage motif and has a truncated carboxy terminus (Ieva et al. 2013).

Import machinery subunits are also targeted for complete degradation by proteases in regulatory and quality-control pathways. TIMM17A is an essential component of the TIMM 23 complex and is a substrate of the ATP-dependent $i$-AAA or yeast mtDNA escape 1-like (YME1L1 or YME1L) protease. YME1L can limit mitochondrial import by degrading TIMM17A at the IMM in response to a number of insults including endoplasmic reticulum (ER) stress (Rainbolt et al. 2013). Furthermore, Yme1 in yeast has also been shown to degrade small Tim proteins Tim9 and Tim10, which function as chaperones assisting the assembly of newly imported membrane inserted carrier translocases (Baker et al. 2012; Rampello and Glynn 2017). Many of these carrier proteins transfer metabolite precursors across the membrane and thus directly impact mitochondrial metabolism. The proteolytic maintenance of mitochondrial import by processing peptidases coupled with the degradation of specific translocase machinery can therefore broadly impact mitochondrial function. For the remainder of this review, we will draw attention to the proteolytic control of other specific mitochondrial func- tions that directly impact mitochondrial and cellular metabolic pathways.

\section{PROTEOLYTIC CONTROL OF MITOCHONDRIAL RESPIRATION}

The production of ATP by OXPHOS can be modulated by regulating the activities of metabolic enzymes, including the assembly of the respiratory chain, the uptake of mitochondrial respiratory substrates, or by altering overall mitochondrial mass. Nuclear and mitochondrial gene expression and protein synthesis machinery must be synchronized and synergized to allow the synthesis and assembly of functional OXPHOS complexes. Their coordination allows mitochondria to respond to ever-changing cellular energy demands and substrate availability. Mitochondrial biogenesis, the maintenance of mtDNA and its replication are under the control of nuclear transcription factors and nuclearencoded mitochondrial proteins (Michel et al. 2012). However, mitochondrial proteases have been shown to participate in both the regulation of mtDNA maintenance and of mitochondrial gene expression to modulate the respiratory activity of cells.

\section{Mitochondrial Genome Maintenance and Gene Expression under the Control of Proteases}

One of the key regulators of mtDNA in mammals is mitochondrial transcription factor $\mathrm{A}$ (TFAM). TFAM is essential for mtDNA replication and transcription (Larsson et al. 1998; Shi et al. 2012) and functions as a histone-like protein packing the mtDNA molecule into mitochondrial nucleoids (Kaufman et al. 2007). The mtDNA copy number faithfully follows levels of TFAM and vice versa. Overexpression of TFAM increases mtDNA levels and TFAM mutation or deletion leads to mtDNA depletion (Ekstrand et al. 2004). Different TFAM:mtDNA ratios have also been postulated to regulate the rate of gene expression. TFAM is phosphorylated by cAMP-dependent protein kinase $\mathrm{A}$ (PKA) and degraded by mitochondrial matrix $\mathrm{AAA}^{+}$peptidase Lon (LONP) (Lu et al. 2013). 
S. Ahola et al.

TFAM binds mtDNA in its dephosphorylated state but the phosphorylated, non-DNA-bound TFAM is degraded by LONP (Fig. 1A). In the case of severe mtDNA depletion, LONP can recognize DNA-free TFAM and degrade it independently of the phosphorylation status of TFAM (Lu et al. 2013). LONP degrades misfolded, oxidized, and damaged proteins (Pinti et al. 2015) and, as new findings reveal, it also degrades functional proteins in a regulatory manner. The yeast Lon protease was found to degrade Abf2 (the yeast TFAM homolog), mtDNA maintenance protein Mgm101, and human mitochondrial replicative helicase Twinkle as well as large ribosomal subunit protein MrpL32 in vitro (Kunova et al. 2017). In addition to its wide range of protein substrates, LONP has also been shown to directly bind mtDNA. In mammalian cells, LONP can bind to the control region of mtDNA that contains promoter regions and an origin of replication in a sequence-specific manner (Lu et al. 2013). In Drosophila cells, LONP was shown to regulate TFAM and mtDNA levels (Matsushima et al. 2010). How the binding of LONP to mtDNA affects the abundance, organization, or reading of mtDNA is still unknown. Regardless, LONP controls mitochondrial genome maintenance in healthy normal cells in addition to its qualitycontrol function degrading damaged or oxidized proteins.

\section{Proteolytic Control of Mitochondrial Protein Synthesis}

Different mitoproteases regulate mitochondrial protein synthesis at multiple sites. Their substrates include proteins that affect messenger RNA (mRNA) processing, ribosomal assembly, and nascent polypeptide chain modifications as well as ribosomal subunits or newly synthesized mitochondrial proteins (Fig. 1B).

Mitochondrial matrix protease complex CLPXP is formed by protease CLPP (ATP-dependent caseinolytic protease) and a chaperone CLPX (ATP-dependent caseinolytic protease X, chaperone subunit). This protease complex has been shown to degrade misfolded or aggregated proteins (Kang et al. 2002; Flynn et al. 2003;
Fischer et al. 2016) in the mitochondrial matrix and it also participates in the mitochondrial unfolded protein response (UPR ${ }^{\mathrm{mt}}$ ) in Caenorhabditis elegans (Haynes et al. 2007). CLPXP has also recently been shown to have an unexpected role in controlling mitochondrial translation and ribosomal assembly in mice (Szczepanowska et al. 2016). CLPXP degrades $12 \mathrm{~S}$ ribosomal RNA (rRNA) chaperone ERAL1 in a timely manner, thus allowing the assembly of ribosomes to promote translation (Fig. 1B). Moreover, CLPXP was also shown to regulate mitochondrial protein synthesis at the mRNA level. In Drosophila cells, CLPXP degrades leucinerich pentatricopeptide repeat domain-containing protein 1 (LRPPRC1), which is needed for polyadenylation of mt-mRNAs, for example, when transcription is inhibited (Matsushima et al. 2017). CLPP deficiency causes a disease characterized by ovarian failure and hearing loss called Perrault syndrome, which is also associated with mutations in the mitochondrial translation and transcription machinery (Perrault et al. 1951; Pierce et al. 2011, 2013; Morino et al. 2014; Chatzispyrou et al. 2017). CLPP depletion in the mouse mimics the human disease, leading to infertility and hearing loss (Gispert et al. 2013; Szczepanowska et al. 2016). It is tempting to speculate that the reported symptoms of these mice, and possibly also humans, are caused by mitochondrial translation defects and the concomitant respiratory deficiency. Indeed, impaired mitochondrial protein synthesis has profound consequences both in mice and human (Boczonadi and Horvath 2014). It should be noted that decreased translation rates in mitochondria lacking CLPP can also have beneficial consequences. The loss of aspartyl aminoacyl tRNA synthetase (DARS2) in the heart leads to cardiomyopathy and early death in mice (Dogan et al. 2014) and deletion of CLPP in this model alleviates cardiac hypertrophy possibly caused by a reduced mitochondrial translation rate (Seiferling et al. 2016).

Another protease that ensures mitochondrial translation is the $m$-AAA protease, which forms a hexameric complex in the IMM with its catalytic domains facing the matrix. In humans, the $m$-AAA protease is a homo-oligomeric 
A

Mitochondrial DNA maintenance and replication

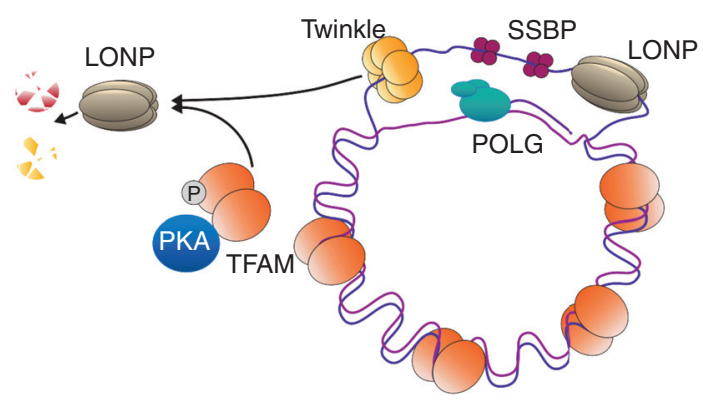

B

Mitochondrial protein synthesis

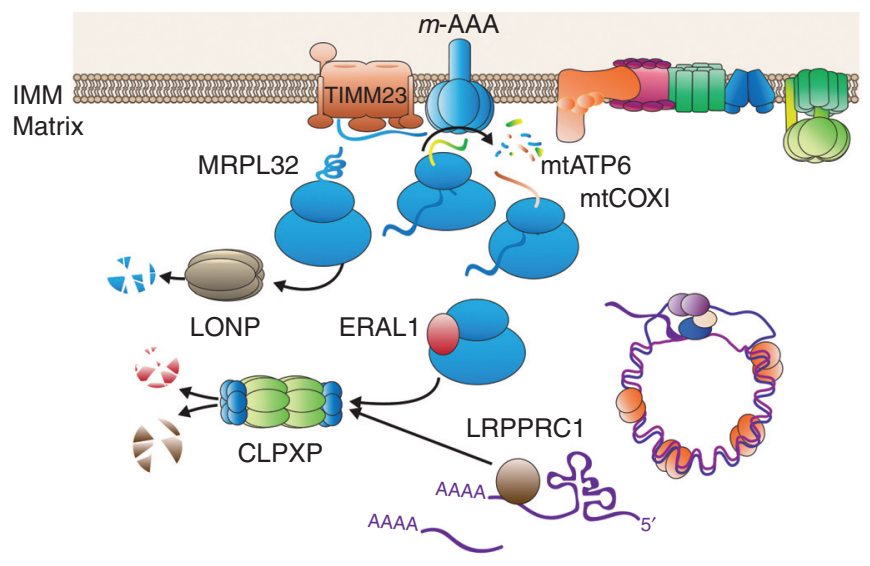

C OXPHOS subunit import and assembly

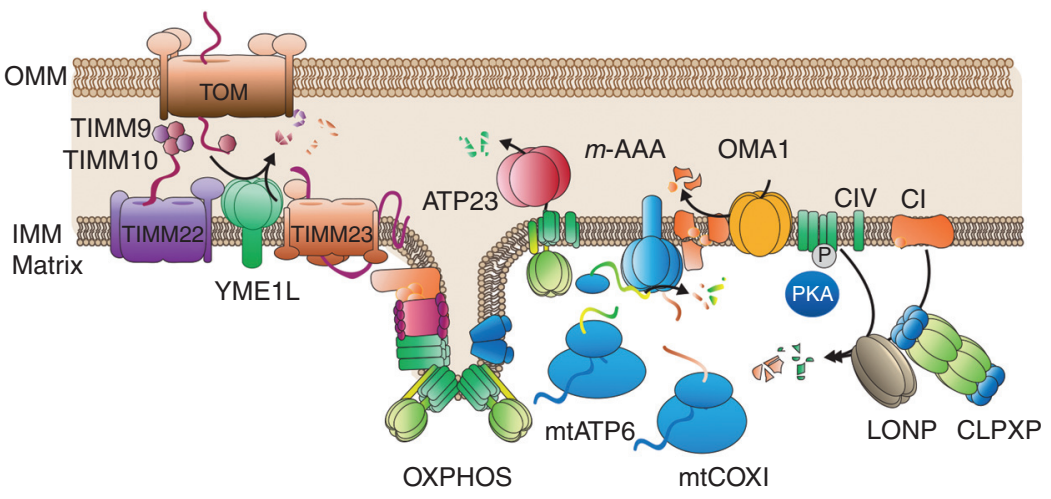

Figure 1. Proteases controlling mitochondrial gene expression and oxidative phosphorylation (OXPHOS) assembly. (A) Peptidase Lon (LONP) regulates mitochondrial genome maintenance and transcription by binding to mitochondrial DNA ( $\mathrm{mtDNA}$ ) and degrading mitochondrial replicative helicase Twinkle and transcription factor A (TFAM). (B) Several proteases control mitochondrial protein synthesis. LONP degrades ribosomal subunit MRPL32 and CLPXP 12S ribosomal RNA (rRNA) chaperone ERAL1 and messenger RNA (mRNA) polyadenylation enzyme leucine-rich pentatricopeptide repeat domain-containing protein 1 (LRPPRC1). Matrix AAA ${ }^{+}$ $\left(m-\mathrm{AAA}^{+}\right)$protease cleaves newly synthesized mitochondrial translation products and MRLP32. (C) OMA1, ATP23, $m$-AAA, YME1L, LONP, and CLPXP are all participating in the degradation of OXPHOS subunits. 
structure composed of AFG3L2 (AFG3-like matrix AAA peptidase subunit 2) subunits or a hetero-oligomeric complex consisting of AFG3L2 and highly homologous SPG7 (Paraplegin) subunits. Mutations in either of these proteins cause OXPHOS dysfunction and neurodegeneration with overlapping but distinct pathologies: spinocerebellar ataxia, in the case of AFG3L2, and spastic paraplegia, in the case of SPG7 (Casari et al. 1998; Di Bella et al. 2010). AFG3L2 mutations in mouse models mimic the human symptoms of severe motor dysfunction and axonal loss (Maltecca et al. 2008, 2009). AFG3L2 controls ribosomal assembly by regulating Mrpl32 maturation in yeast (Nolden et al. 2005). Similarly, the loss of AFG3L2 in mammalian cells impairs mitochondrial ribosome assembly and protein synthesis (Almajan et al. 2012). Together, these studies show that proteases take part in the intrinsic regulatory pathway of mitochondrial gene expression (Fig. 1B). In addition, the $m$-AAA protease also exerts quality-control functions (Arlt et al. 1998; Leonhard et al. 2000) and modulates mitochondrial calcium homeostasis by regulating the assembly of the mitochondrial calcium uniporter (MCU) (Konig et al. 2016; Patron et al. 2018).

Proteases Acutely Control OXPHOS Complex Assembly and Activity

The IMM accommodates mitochondrial respiratory chain complexes (complex I-IV) that function as electron carriers creating a protonmotive force of $\mathrm{pH}$ and membrane potential across the IMM that allows ATP production by the $\mathrm{F}_{1} \mathrm{~F}_{0}$ ATP synthase (complex V) (Chaban et al. 2014). Mitoproteases are emerging as central regulators of the assembly of these complexes and thereby control cellular ATP production (Fig. 1C).

The formation of a functional respiratory chain depends on the coordinated assembly of nuclear-encoded subunits, which must be imported into mitochondria after their synthesis on cytosolic ribosomes, with mt-encoded respiratory chain subunits. Various mitoproteases degrade nonassembled subunits and thus prevent potential damaging effects (Arlt et al. 1998;
Hornig-Do et al. 2012; Stiburek et al. 2012; Richter et al. 2015). Moreover, they play direct roles during the assembly of OXPHOS complexes and of the $\mathrm{F}_{1} \mathrm{~F}_{0}$ ATP synthase. In yeast, the processing peptidase Atp23 was shown to be essential for ATPase $\mathrm{F}_{1} \mathrm{~F}_{0}$ assembly by controlling both the maturation Atp6 subunits synthesized within mitochondria and their subsequent assembly (Osman et al. 2007; Zeng et al. 2007). The zinc metalloprotease Oma1 degrades selectively Cox1 subunits if the assembly of cytochrome $c$ oxidase (COX) is impaired in yeast mutant cells (Khalimonchuk et al. 2012; Bohovych et al. 2015). Heme is an essential cofactor for respiratory chain enzymes and its synthesis is regulated by CLPXP. CLPXP degrades the rate-limiting enzyme in heme synthesis, ALAS1, which curbs heme accumulation in mitochondria (Kardon et al. 2015; Kubota et al. 2016). Mutations in CLPX causes erythropoietic protoporphyria in human patients (Yien et al. 2017).

Proteases are also required to regulate OXPHOS function acutely when a cell needs to adapt to sudden metabolic changes. Hypoxia is one example of a situation in which mitochondrial metabolism must be matched with altered cellular metabolism. Hypoxia-inducible factor $(\mathrm{HIF}-1 \alpha)$ is a transcriptional activator that promotes a metabolic shift during hypoxia by up-regulating glycolysis and down-regulating mitochondrial respiration, a hallmark of many cancers. LONP mRNA is up-regulated on HIF$1 \alpha$ stabilization and its subsequent accumulation leads to enhanced degradation of the complex IV subunit COX4-1 (Fukuda et al. 2007). This occurs alongside the transcriptional up-regulation of an alternative subunit, COX42 , which may optimize $\mathrm{O}_{2}$ usage during hypoxia to suppress oxidative stress (Fukuda et al. 2007; Sepuri et al. 2017). Interestingly, LONP expression is enhanced in some tumors and its downregulation can consequently promote cancer cell death in vitro and block melanoma metastasis in vivo (Hu et al. 2005; Bernstein et al. 2012; Quiros et al. 2014). Although a complete loss of LONP causes embryonic lethality, heterozygous mice are viable and are protected from colon carcinoma and skin tumors (Quiros et al. 2014). The 
Mitochondrial Proteolysis and Metabolic Control

remodeling of complex IV by LONP may be central to its apparent oncogenic potential because it supports the shift toward glycolysis. Additionally, LONP and CLPP together specifically degrade the peripheral arm of complex I in response to a loss of membrane potential and increasing levels of ROS in mammalian cells (Pryde et al. 2016). This partial degradation of complex I limited further ROS production and cellular damage under these conditions.

\section{PROTEASES TUNE THE MITOCHONDRIAL DYNAMICS MACHINERY TO REGULATE CELLULAR METABOLISM}

Another key feature of mitochondrial biology that exists under close proteolytic control is mitochondrial dynamics. The modification of mitochondrial morphology represents an important facet of mitochondrial quality control and is intricately coupled to the metabolic status of cells. The fusion of mitochondria into elongated networks is balanced by fission events that can isolate individual mitochondria or, if unopposed, can lead to a complete fragmentation of the mitochondrial network (Youle and van der Bliek 2012). The elongation of a mitochondrial network is associated with high demands for OXPHOS, whereas metabolic shifts toward glycolysis correlate with a fragmented mitochondrial morphology (Mishra and Chan 2016; Wai and Langer 2016). The physiological importance of this relationship between mitochondrial morphology and metabolism has been highlighted, for example, during tumorigenesis, stem cell differentiation and T-cell programming (Buck et al. 2016; Chen and Chan 2017). The fragmentation of mitochondria also facilitates the removal of dysfunctional or redundant organelles by the quality-control pathway called mitophagy (discussed in the following section). Differing metabolic inputs and demands can rapidly alter the morphology of mitochondria by targeting their conserved dynamics machinery via posttranslational modification pathways. Mitochondrial proteolysis has emerged as a central regulator of the mitochondrial dynamics machinery at both membranes.

\section{Proteolytic Control of OMM Dynamics}

Mitochondrial fusion and fission are orchestrated by a conserved set of dynamin-related GTPases. Fusion of the OMM is mediated by mitofusin 1 and 2 (MFN1/2); homologous proteins that are anchored to the OMM. Hetero- or homotypic interactions between mitofusins of opposing mitochondria promotes their tethering (Daumke and Roux 2017). Ablation of MFN1 or MFN2 leads to mitochondrial fragmentation and specific mutations in MFN2 cause the recessive peripheral neuropathy Charcot-Marie-Tooth type 2A (Cartoni and Martinou 2009). Mitofusins are ubiquitylated, which can either promote MFN1/2-mediated fusion or target them for degradation by the $26 \mathrm{~S}$ proteasome. The OMM localized cysteine ubiquitinspecific protease 30 (USP30), which is currently the only known integral OMM protease, negatively regulates mitochondrial fusion by cleaving profusion ubiquitin moieties from the mitofusins (Fig. 2) (Nakamura and Hirose 2008; Yue et al. 2014). Indeed, the suppression of USP30 by knockdown or chemical inhibition stimulates mitochondrial fusion and can restore the mitochondrial network and the OXPHOS capacity of $M f n 1^{-/-}$and $M f n 2^{-/-}$cells (Yue et al. 2014).

Mitochondrial fission at the OMM is also regulated by proteolysis but may involve proteases that are not constitutively present at mitochondria. Fission is driven by the recruitment of the large cytoplasmic GTPase DRP1 to sites marked by fission receptor proteins MFF, MiD49, and MiD51 (Kraus and Ryan 2017). Subsequent oligomerization at these sites facilitates mitochondrial constriction and ultimately leads to scission in collaboration with another dynamin family member, dynamin-2 (Lee et al. 2016). DRP1 activity is coupled to cellular energy status, for example, starvation conditions block DRP1 recruitment to mitochondria to preserve an elongated mitochondrial network, whereas the regulation of DRP1 by the circadian clock supports a rhythmic relationship between mitochondrial dynamics and ATP production (Gomes et al. 2011; Rambold et al. 2011; Schmitt et al. 2018). Consequently, much focus has been placed on the posttranslational regulation of 
S. Ahola et al.
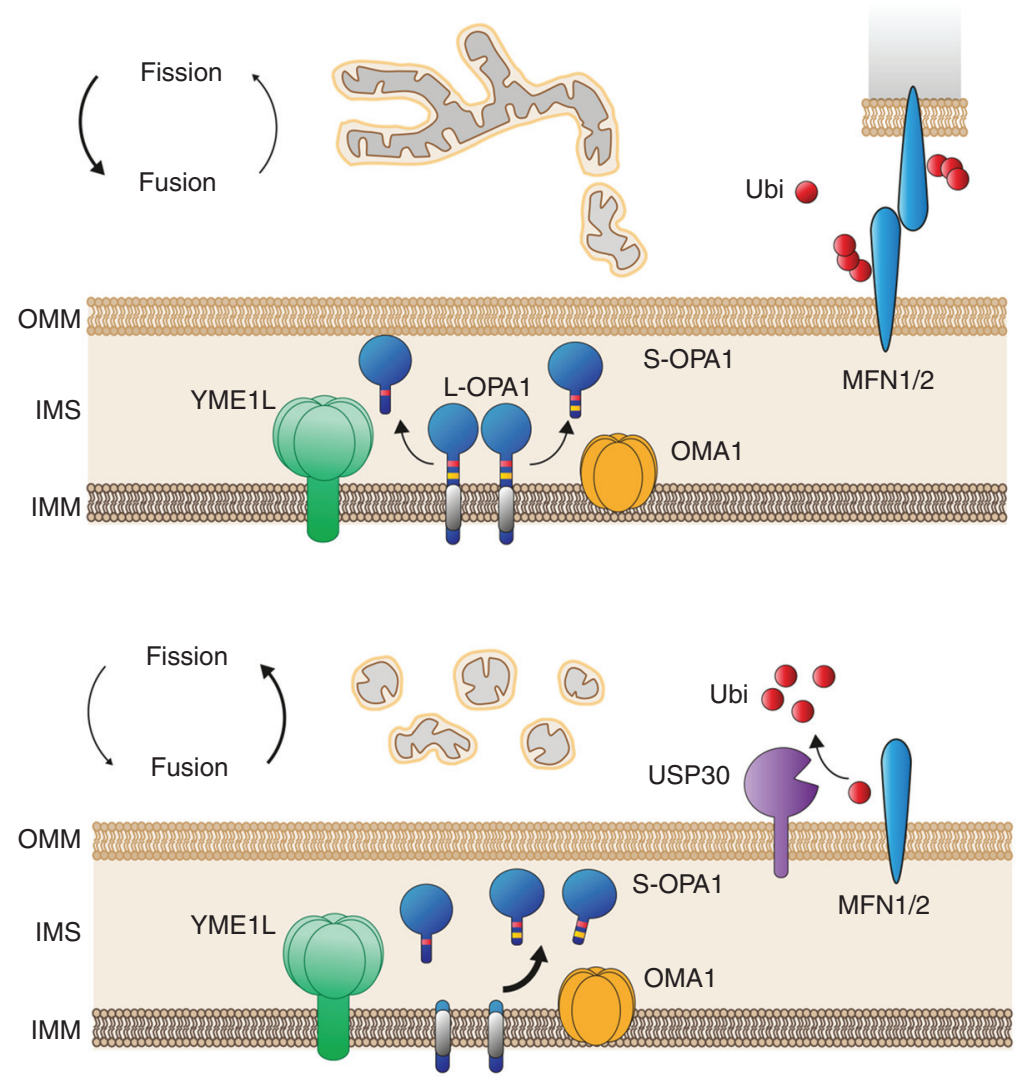

Figure 2. Proteolytic control of mitochondrial dynamics. Mitochondrial fusion (upper) and fission (lower) depend on the regulation of mitochondrial dynamics factors by proteolysis. MFN1 and MFN2 promote outer mitochondrial membrane (OMM) fusion and they are negatively regulated by the deubiquitinase USP30. YME1L and OMA1 process OPA1 to regulate inner mitochondrial membrane (IMM) fusion. Excessive processing of membrane-bound long-form (L)-OPA1 by OMA1 limits fusion and promotes mitochondrial division.

DRP1, predominantly by phosphorylation, but also by SUMOylation and ubiquitylation. Phosphatases, deubiquitylases and deSUMOylases thus may modulate DRP1 fission activity in response to specific metabolic and stress stimuli. The deSUMOylase SENP3, for instance, has been shown to promote DRP1 interaction with MFF and to drive mitochondrial fission and cell death in response to oxidative stress (Guo et al. 2013, 2017). A seemingly contradictory role for another peptidase, SENP2, in the regulation of DRP1 SUMOylation highlights the need for further work to understand the proteolytic control of mitochondrial fission at the OMM (Fu et al. 2014).

\section{Proteolytic Control of IMM Dynamics and Ultrastructure}

Mitochondrial fusion at the IMM is elaborately regulated by the proteolytic processing of the pro-fusion GTPase optic atrophy 1 (OPA1) (MacVicar and Langer 2016). OPAl mediates both IMM fusion and cristae biogenesis, which places it as a key regulator of mitochondrial dynamics, apoptosis, and respiration (Olichon et al. 2006). Loss of OPA1 in cells causes complete mitochondrial fragmentation, mtDNA loss, and respiratory dysfunction. As its name indicates, OPA1 mutation leads to autosomal-dominant optic atrophy, a neuropathy that presents 
a progressive deterioration of retinal ganglion cells and the optic nerve (Alexander et al. 2000; Delettre et al. 2000).

OPA1 regulation is complex. Eight alternatively spliced mRNA isoforms exist in humans and after import and tethering to the IMM, long (L)-OPA1 forms are proteolytically processed to release short (S)-OPA1 into the IMS (Fig. 2). Homeostasis between L-OPA1 and S-OPA1 is maintained by YME1L and OMA1 and these integral IMM membrane proteases target OPA1 at distinct individual processing sites exposed to the IMS (Ishihara et al. 2006). Unlike its yeast homolog Mgm1, which is only processed by a single protease, the rhomboid protease Pcp1 (Herlan et al. 2003, 2004), the cleavage of L-OPA1 by two proteases allows both constitutive and inducible proteolytic control of OPA1. The analysis of cells expressing exclusively L- or S-OPA1 variants as well as cells lacking the OPA1-processing peptidases YME1L and OMA1 revealed that L-OPA1 is necessary and sufficient to promote mitochondrial fusion (Anand et al. 2014; Del Dotto et al. 2017; Lee et al. 2017). In contrast, expression of S-OPA1 was found to be sufficient to stabilize mtDNA and maintain cristae morphogenesis in $\mathrm{Opa1}^{-1-}$ cells (Del Dotto et al. 2017; Lee et al. 2017). Thus, proteolytic processing by YME1L or OMA1 offers an intriguing possibility to acutely modulate the fusion activity of OPA1 in response to mitochondrial stressors and altered metabolic demands.

The zinc metalloprotease OMA1 is activated by mitochondrial dysfunction, resulting for instance from IMM depolarization, mitochondrial ATP depletion, or by the loss of other IMM proteins such as YME1L, DNAJC19, and the m-AAA protease (Anand et al. 2014; Baker et al. 2014; Richter-Dennerlein et al. 2014; Rainbolt et al. 2016). The subsequent cleavage of L-OPA1 and accumulation of S-OPA1 limits mitochondrial fusion and facilitates fission, resulting in fragmentation of the mitochondrial network and an increased sensitization to apoptosis (Anand et al. 2014). Similarly, various stress conditions, including ROS, heat stress and apoptotic stimuli can trigger OMA1 activation and mitochondrial fragmentation (Baker
Mitochondrial Proteolysis and Metabolic Control

et al. 2014; Jiang et al. 2014; Faccenda et al. 2017; Silic-Benussi et al. 2018). It remains to be properly defined how the loss of this response contributes to the relatively mild metabolic phenotypes present in $\mathrm{Omal}^{-/-}$mice (Quiros et al. 2012). Conversely, OMA1 hyperactivation has been shown to cause tissue atrophy in models of neurodegeneration, cardiomyopathy, and renal injury (Xiao et al. 2014; Wai et al. 2015; Korwitz et al. 2016). Indeed, targeting OMA1 holds significant therapeutic potential. For instance, OMA1 ablation is cardioprotective in four mouse models of heart failure and the overexpression of its substrate OPA1 also protects against degeneration in a number of tissues including the heart (Civiletto et al. 2015; Varanita et al. 2015; Wai et al. 2015; Acin-Perez et al. 2018). Targeting the protease itself would arguably be more clinically applicable and may avoid unwanted side effects attributed to high levels of OPA1 overexpression in vivo (Civiletto et al. 2015; Acin-Perez et al. 2018).

Although OMA1 can be regarded as a stressinducible OPA1-processing peptidase, the ATPdependent $i$-AAA protease YME1L is regulated by different metabolic inputs. YME1L was reported to process OPA1 more readily in mitochondria with high levels of OXPHOS, correlating with an increase in network connectivity (Mishra et al. 2014). In addition, YME1L is required to promote mitochondrial hyperfusion in cells undergoing acute ER stress (Rainbolt et al. 2013; Lebeau et al. 2018). However, during these conditions, OPA1 processing remains unaltered and perhaps YME1L-dependent processing or degradation of one or multiple additional substrate(s) may be of significance in this context to facilitate mitochondrial morphology adaptation.

\section{MITOCHONDRIAL PROTEOLYSIS AND LIPID METABOLISM}

The regulation of membrane lipid accumulation is another emerging role of mitoproteases that is intimately linked to cellular metabolism. Mitochondria participate in lipid homeostasis by synthesizing and degrading phospholipids, sphingolipids, and sterols (Horvath and Daum 
S. Ahola et al.

2013). Mitochondria are able to synthesize some lipids independently, such as phosphatidylethanolamine (PE), phosphatidic acid (PA), phosphatidylglycerol (PG), and cardiolipin (CL), the latter of which is specific to mitochondria but is still highly dependent on precursor lipids, which are synthesized in the ER and transported to mitochondria and across the IMS (Tatsuta and Langer 2017). Shuttling of phospholipids across the IMS is mediated by conserved lipid transfer proteins in a lipid-specific manner, all of which turn out to be under proteolytic control. Mitoproteases thus regulate the phospholipid composition of mitochondrial membranes by limiting the accumulation of lipid transfer proteins in the IMS. Members of the Ups/PRELI protein family, PRELID1 (Ups1 in yeast) and PRELID3B (Ups2 in yeast), are in a heterodimeric complex with TRIAP1 (Mdm35 in yeast) and are responsible for transporting $\mathrm{PA}$ and phosphatidylserine (PS) across the IMS, respectively. They accumulate at low levels within the IMS owing to ongoing proteolysis by Yme1 (Fig. 3) (Potting et al. 2010; Connerth et al. 2012; Watanabe et al. 2015; Aaltonen et al. 2016; Miyata et al. 2016). Studies in yeast suggest that binding of Ups1 to the IMM and its subsequent degradation by Yme1 is modulated by CL levels in the IMM (Connerth et al. 2012). Similarly, YME1L degrades the START (StAR-related lipid transfer) domain-containing lipid transfer protein STARD7, which mediates phosphatidylcholine (PC) transfer to the IMM (Saita et al. 2018). Interestingly, STARD7 is dually localized in the IMS and the cytosol. PARL cleavage of STARD7 during its import into mitochondria allows its kinetic partitioning between the IMS and the cytosol (Saita et al. 2018). Another member of the START family of lipid transfer proteins, STARD1, transports cholesterol to mitochondria (Martin et al. 2016) and is degraded after import into the mitochondrial matrix (Granot et al. 2007).

Lipid synthesis enzymes within mitochondria are also targeted by mitoproteases. Mitochondrial PE synthesis from PS is catalyzed by mitochondrial phosphatidylserine decarboxylase 1 (Psd1) in yeast. Newly imported Psd1 is processed by MPP and the metalloendopeptidase Octl (Horvath et al. 2012) and its membrane insertion is accompanied by an autocatalytic cleavage event that is required for its PS

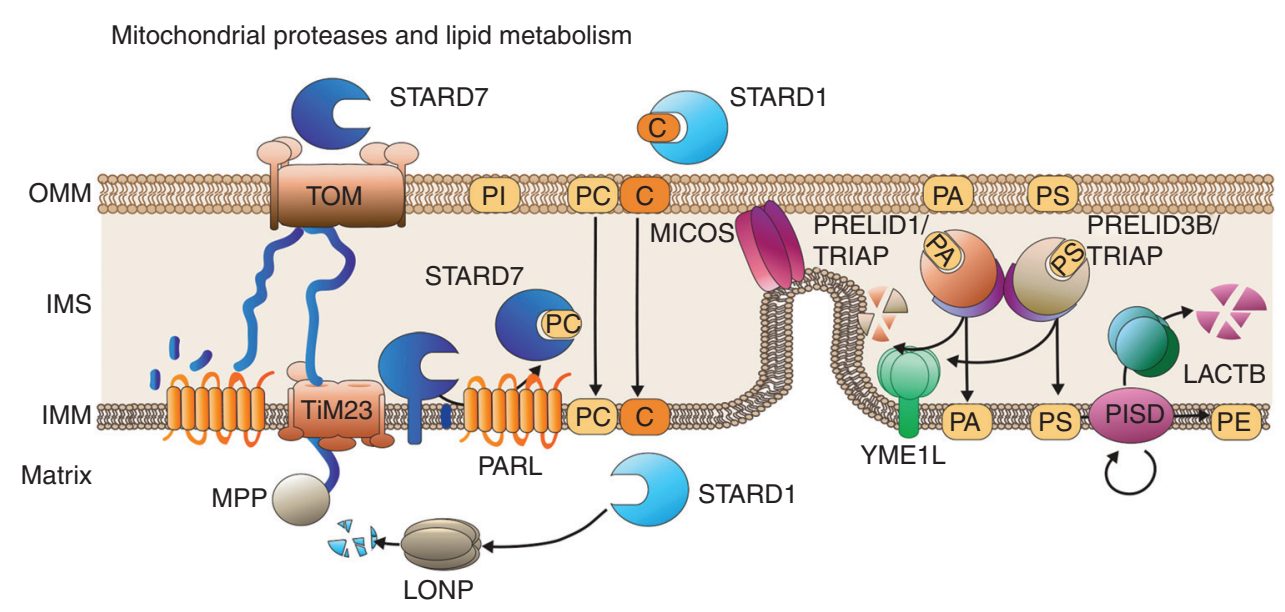

Figure 3. Mitochondrial proteases and lipid metabolism. PARL processes lipid transfer protein STARD7 and regulates its localization between mitochondria and cytoplasm. STARD1 transports cholesterol (C) to the outer mitochondrial membrane (OMM) but can be degraded by LONP in the matrix. The PRELID1-TRIAP complex and PRELID3B-TRIAP complex transport phosphatidic acid (PA) and phosphatidyl serine (PS), respectively, across the intermembrane space (IMS) and are degraded by YME1L. Phosphatidylserine carboxylase (PSD1) is cleaved by LACTB and PSD1 is also processing itself and thus switching from protease into a decarboxylase. 
decarboxylase activity (Choi et al. 2012; Horvath et al. 2012). Although misfolded yeast Psd1 is degraded by Yme1 and Oma1, both exerting quality-control functions, the mammalian homolog PISD is under proteolytic control by LACTB (Keckesova et al. 2017), a mitochondrial IMS protein related to the bacterial penicillinbinding/ $\beta$-lactamase protein family. $L A C T B$ was identified as a novel tumor suppressor gene, whose function is linked to the PISD-PE axis highlighting the importance of mitochondrial lipid metabolism for the control of cell proliferation (Fig. 3) (Keckesova et al. 2017).

\section{PROTEOLYSIS AND ORGANELLAR QUALITY CONTROL BY MITOPHAGY}

Mitophagy regulates mitochondrial mass and quality by selectively targeting redundant or dysfunctional mitochondria for destruction in the lysosome via the autophagy machinery. $\mathrm{Mi}$ tophagy is also regarded to be important for regulating metabolic homeostasis in a number of physiological contexts (Rodger et al. 2018). For instance, the clearance of mitochondria is required to support a switch to glycolysis during retinal ganglion cell differentiation (EstebanMartinez et al. 2017) and to support cancer cell survival after mitotic arrest (Domenech et al. 2015). The increasing number of mitophagy regulated physiological scenarios is mirrored by the continued discovery of novel mitophagy pathways. The signaling for mitochondrial engulfment by nascent autophagosomes depends on the exposure of mitophagy receptor proteins and signals on the mitochondrial surface (Rodger et al. 2018), and IMM proteases have emerged as key players in several surveillance mechanisms that exist to target particular mitochondria for mitophagy. Indeed, the first example of this was described in yeast in which Yme1 was found to regulate mitophagy by directly processing the OMM mitophagy receptor Atg32 (Wang et al. 2013). Although a mammalian homolog for Atg32 has been proposed, it remains to be seen whether YME1L regulates mitophagy in mammals (Murakawa et al. 2015).

In mammalian cells, PINK1/Parkin-mediated mitophagy has received a great deal of atten-
Mitochondrial Proteolysis and Metabolic Control

tion because mutations in the kinase PINK1 and the E3-ubiquitin ligase Parkin were found to cause autosomal-recessive Parkinson's disease (Pickrell and Youle 2015). Both proteins act in the same mitophagy pathway, which begins with the stabilization of PINK1 on the OMM of dysfunctional mitochondria and is followed by the mitochondrial recruitment of Parkin and the subsequent ubiquitination of OMM proteins to recruit the autophagy machinery (Fig. 4) (Durcan and Fon 2015; Pickrell and Youle 2015). The deubiquitinase USP30 negatively regulates mitophagy by removing ubiquitin signals from Parkin target proteins (Bingol et al. 2014; Cunningham et al. 2015). Surprisingly, USP30 depletion can even enhance mitophagy in cells lacking detectable Parkin, suggesting that it deubiquitinates specific OMM proteins to restrict basal mitophagy (Marcassa et al. 2018).

PINK1 was the first substrate of the rhomboid protease PARL to be identified and constitutive PINK1 processing at the IMM of healthy mitochondria promotes its retro-translocation to the cytosol for subsequent degradation by the 26S proteasome (Jin et al. 2010; Meissner et al. 2011; Greene et al. 2012; Yamano and Youle 2013). However, mitochondrial damage and a loss of mitochondrial membrane potential ( $\Delta \Psi \mathrm{mt}$ ) blocks the insertion of PINK1 into the IMM, thereby preventing its cleavage by PARL (Jin et al. 2010; Meissner et al. 2011). This results in the accumulation of PINK1 in the OMM as a positive signal for mitophagy. Intriguingly, PARL processing of PINK1 is also directly regulated by mitochondrial metabolism. During mitochondrial metabolic crisis and reduced ATP production, PARL is cleaved at the amino terminus via an autocatalytic mechanism regulated by the matrix kinase PDK2 (Sík et al. 2004; Shi and McQuibban 2017). This processed form of PARL, termed PACT (PARL carboxyl terminus), has reduced catalytic activity and may facilitate the accumulation of PINK1 on dysfunctional mitochondria (Shi and McQuibban 2017). PARL autocatalysis also releases the short amino-terminal sequence of PARL termed $\mathrm{p} \beta$ (Sík et al. 2004). The $\mathrm{p} \beta$ peptide has been reported to localize to the nucleus and to facil- 
S. Ahola et al.
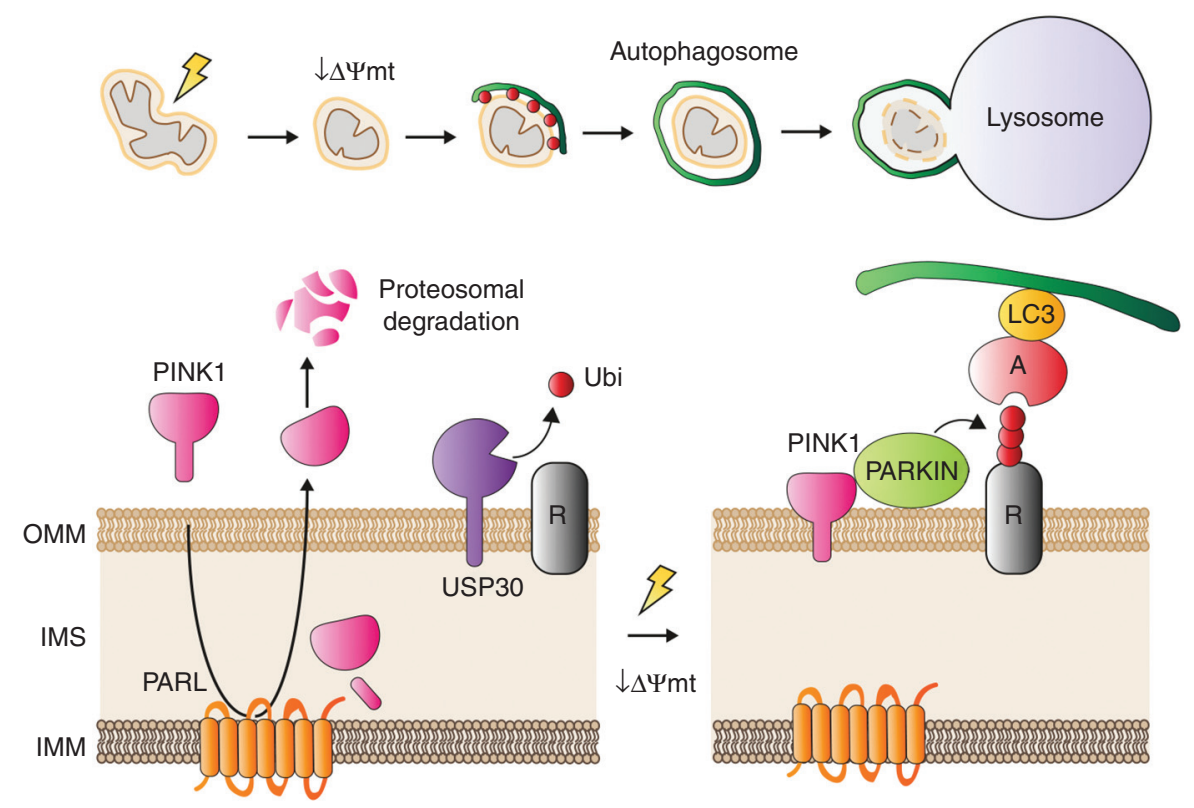

Figure 4. Proteolytic regulation of PINK1/Parkin mitophagy. In a healthy mitochondrion with a normal membrane potential $(\Delta \Psi \mathrm{mt})$, PARL processes newly imported PINK1 at the inner mitochondrial membrane (IMM), which subsequently leaves the mitochondrion and is degraded by the proteasome. Mitochondrial dysfunction blocks PINK1 import and promotes PINK1 accumulation in the outer mitochondrial membrane (OMM). Here, PINK1 selectively recruits the E3-ligase Parkin, which ubiquitylates mitophagy receptor (R) proteins; an action suppressed in healthy mitochondria by USP30 deubiquitylase activity. These ubiquitin signals are recognized by mitophagy adaptor (A) proteins that interact with the autophagosomal protein LC3, resulting in the engulfment of the mitochondrion and delivery to the lysosome.

itate the transcriptional up-regulation of mitochondrial biogenesis (Civitarese et al. 2010). It is certainly fascinating to consider that PARL proteolysis contributes to metabolic homeostasis by simultaneously regulating the removal and replacement of dysfunctional mitochondria.

Interestingly, other identified PARL substrates have been reported to show dual-localization, which includes the proapoptotic protein Smac/DIABLO, the lipid transfer protein STARD7 and the Ser/Thr phosphatase phosphoglycerate mutase 5 (PGAM5) (Sekine et al. 2012; Saita et al. 2017, 2018). PGAM5 dephosphorylation of the mitophagy receptor FUNDC1 at the OMM promotes mitophagy during hypoxia (Chen et al. 2014; Wu et al. 2014). In stark contrast to PINK1 processing, PARL cleavage of PGAM5 is enhanced by mitochondrial depolarization and, albeit to a lesser degree, during hypoxia (Sekine et al. 2012; Chen et al. 2014; Saita et al. 2017). Depolarizationinduced processing occurs in conjunction with enhanced OMA1-mediated cleavage of PGAM5 and results in the rapid dissociation of PGAM5 from the IMM (Sekine et al. 2012; Wai et al. 2016). How PGAM5 relocates to the mitochondrial surface after processing by PARL and how the coordinated processing of PGAM5 by PARL and OMA1 contributes to mitophagy regulation during stress remains to be explained. Furthermore, the proteolytic release of PGAM5 from the IMM is likely to influence mitochondrial metabolism in multiple ways. For example, Bernkopf et al. (2018) recently reported that stimulated PGAM5 cleavage by PARL during mitochondrial depolarization or hypoxia results in PGAM5 release into the cytosol, where it can boost mitochondrial biogenesis by dephosphorylating $\beta$-catenin ultimately resulting in enhanced nuclear gene transcription. 


\section{CONCLUDING REMARKS}

This review of the multiple mitochondrial functions under proteolytic control has highlighted the importance of mitoproteases in metabolic adaptation. Given the central role of proteolysis for mitochondrial activities, it is arguably not surprising that a steadily increasing number of mitoproteases have been associated with disease and that the strong phenotypes observed due to the loss of mitoproteases share similarities with general mitochondriopathies. Importantly, these phenotypes may be altered under stress or different metabolic conditions, reflecting the plasticity of the mitochondrial proteome and the central role of proteolysis in adaptive processes. Mitoproteases therefore require tight regulation and we are only beginning to place them within cellular signaling networks. Identifying the specific stressors and metabolic conditions that regulate mitoproteases, in addition to unveiling their novel substrates, will help us to realize their therapeutic potential. Combining such findings with insights into the protein structure and working mechanisms of these enzymes will facilitate the development of mitoprotease agonists and antagonists to target specific human diseases and to support healthy aging.

\section{ACKNOWLEDGMENTS}

This work was supported by grants from the Deutsche Forschungsgemeinschaft and the Max-Planck-Society.

\section{REFERENCES}

Aaltonen MJ, Friedman JR, Osman C, Salin B, di Rago JP, Nunnari J, Langer T, Tatsuta T. 2016. MICOS and phospholipid transfer by Ups2-Mdm35 organize membrane lipid synthesis in mitochondria. J Cell Biol 213: 525-534. doi:10.1083/jcb.201602007

Acin-Perez R, Lechuga-Vieco AV, Del Mar Munoz M, NietoArellano R, Torroja C, Sanchez-Cabo F, Jimenez C, Gonzalez-Guerra A, Carrascoso I, Beninca C, et al. 2018. Ablation of the stress protease OMA1 protects against heart failure in mice. Sci Transl Med 10: eaan4935. doi:10.1126/ scitranslmed.aan 4935

Alexander C, Votruba M, Pesch UE, Thiselton DL, Mayer S, Moore A, Rodriguez M, Kellner U, Leo-Kottler B, Auburger $\mathrm{G}$, et al. 2000. OPA1, encoding a dynamin-related GTPase, is mutated in autosomal dominant optic atrophy linked to chromosome 3q28. Nat Genet 26: 211-215. doi:10.1038/79944

Almajan ER, Richter R, Paeger L, Martinelli P, Barth E, Decker T, Larsson NG, Kloppenburg P, Langer T, Rugarli EI. 2012. AFG3L2 supports mitochondrial protein synthesis and Purkinje cell survival. J Clin Invest 122: 40484058. doi:10.1172/JCI64604

Anand R, Wai T, Baker MJ, Kladt N, Schauss AC, Rugarli E, Langer T. 2014. The $i$-AAA protease YME1L and OMA1 cleave OPA1 to balance mitochondrial fusion and fission. J Cell Biol 204: 919-929. doi:10.1083/jcb.201308006

Arlt H, Steglich G, Perryman R, Guiard B, Neupert W, Langer T. 1998. The formation of respiratory chain complexes in mitochondria is under the proteolytic control of the $m$-AAA protease. EMBO J 17: 4837-4847. doi: $10.1093 / \mathrm{emboj} / 17.16 .4837$

Baker MJ, Mooga VP, Guiard B, Langer T, Ryan MT, Stojanovski D. 2012. Impaired folding of the mitochondrial small TIM chaperones induces clearance by the $i$-AAA protease. J Mol Biol 424: 227-239. doi:10.1016/j.jmb. 2012.09.019

Baker MJ, Lampe PA, Stojanovski D, Korwitz A, Anand R, Tatsuta T, Langer T. 2014. Stress-induced OMA1 activation and autocatalytic turnover regulate OPA1-dependent mitochondrial dynamics. EMBO J 33: 578-593. doi:10.1002/embj.201386474

Bernkopf DB, Jalal K, Brückner M, Knaup KX, Gentzel M, Schambony A, Behrens J. 2018. Pgam5 released from damaged mitochondria induces mitochondrial biogenesis via Wnt signaling. J Cell Biol 217: 1383-1394. doi:10.1083/jcb.201708191

Bernstein SH, Venkatesh S, Li M, Lee J, Lu B, Hilchey SP, Morse KM, Metcalfe HM, Skalska J, Andreeff M, et al. 2012. The mitochondrial ATP-dependent Lon protease: A novel target in lymphoma death mediated by the synthetic triterpenoid CDDO and its derivatives. Blood 119: 3321-3329. doi:10.1182/blood-2011-02-340075

Bertelsen B, Melchior L, Jensen LR, Groth C, Glenthoj B, Rizzo R, Debes NM, Skov L, Brondum-Nielsen K, Paschou $\mathrm{P}$, et al. 2014. Intragenic deletions affecting two alternative transcripts of the IMMP2L gene in patients with Tourette syndrome. Eur J Hum Genet 22: 1283 1289. doi:10.1038/ejhg.2014.24

Bingol B, Tea JS, Phu L, Reichelt M, Bakalarski CE, Song Q Foreman O, Kirkpatrick DS, Sheng M. 2014. The mitochondrial deubiquitinase USP30 opposes parkin-mediated mitophagy. Nature 510: 370-375. doi:10.1038/ nature 13418

Boczonadi V, Horvath R. 2014. Mitochondria: Impaired mitochondrial translation in human disease. Int J Biochem Cell Biol 48: 77-84. doi:10.1016/j.biocel.2013.12.011

Bohovych I, Fernandez MR, Rahn JJ, Stackley KD, Bestman JE, Anandhan A, Franco R, Claypool SM, Lewis RE, Chan SS, et al. 2015. Metalloprotease OMA1 fine-tunes mitochondrial bioenergetic function and respiratory supercomplex stability. Sci Rep 5: 13989. doi:10.1038/srep 13989

Buck MD, O’Sullivan D, Klein Geltink RI, Curtis JD, Chang CH, Sanin DE, Qiu J, Kretz O, Braas D, van der Windt GJ, et al. 2016. Mitochondrial dynamics controls T cell fate through metabolic programming. Cell 166: 63-76. doi:10.1016/j.cell.2016.05.035 
S. Ahola et al.

Cartoni R, Martinou JC. 2009. Role of mitofusin 2 mutations in the physiopathology of Charcot-Marie-Tooth disease type 2A. Exp Neurol 218: 268-273. doi:10.1016/j expneurol.2009.05.003

Casari G, De Fusco M, Ciarmatori S, Zeviani M, Mora M Fernandez P, De Michele G, Filla A, Cocozza S, Marcon R, et al. 1998. Spastic paraplegia and OXPHOS impairment caused by mutations in paraplegin, a nuclearencoded mitochondrial metalloprotease. Cell 93: 973 983. doi:10.1016/S0092-8674(00)81203-9

Chaban Y, Boekema EJ, Dudkina NV. 2014. Structures of mitochondrial oxidative phosphorylation supercomplexes and mechanisms for their stabilisation. Biochim Biophys Acta 1837: 418-426. doi:10.1016/j.bbabio. 2013.10.004

Chatzispyrou IA, Alders M, Guerrero-Castillo S, Zapata Perez R, Haagmans MA, Mouchiroud L, Koster J, Ofman R, Baas F, Waterham HR, et al. 2017. A homozygous missense mutation in ERAL1, encoding a mitochondrial rRNA chaperone, causes Perrault syndrome. Hum Mol Genet 26: 2541-2550. doi:10.1093/hmg/ddx152

Chen H, Chan DC. 2017. Mitochondrial dynamics in regulating the unique phenotypes of cancer and stem cells. Cell Metab 26: 39-48. doi:10.1016/j.cmet.2017.05.016

Chen G, Han Z, Feng D, Chen Y, Chen L, Wu H, Huang L, Zhou C, Cai X, Fu C, et al. 2014. A regulatory signaling loop comprising the PGAM5 phosphatase and CK2 controls receptor-mediated mitophagy. Mol Cell 54: 362-377. doi:10.1016/j.molcel.2014.02.034

Choi JY, Augagneur Y, Ben Mamoun C, Voelker DR. 2012. Identification of gene encoding Plasmodium knowlesi phosphatidylserine decarboxylase by genetic complementation in yeast and characterization of in vitro maturation of encoded enzyme. J Biol Chem 287: 222-232. doi:10.1074/jbc.M111.313676

Choquet K, Zurita-Rendon O, La Piana R, Yang S, Dicaire MJ, Care4Rare C, Boycott KM, Majewski J, Shoubridge EA, Brais B, et al. 2016. Autosomal recessive cerebellar ataxia caused by a homozygous mutation in PMPCA. Brain 139: e19. doi:10.1093/brain/awv362

Civiletto G, Varanita T, Cerutti R, Gorletta T, Barbaro S, Marchet S, Lamperti C, Viscomi C, Scorrano L, Zeviani M. 2015. Opal overexpression ameliorates the phenotype of two mitochondrial disease mouse models. Cell Metab 21: 845-854. doi:10.1016/j.cmet.2015.04.016

Civitarese AE, MacLean PS, Carling S, Kerr-Bayles L, McMillan RP, Pierce A, Becker TC, Moro C, Finlayson J, Lefort N, et al. 2010. Regulation of skeletal muscle oxidative capacity and insulin signaling by the mitochondrial rhomboid protease PARL. Cell Metab 11: 412-426. doi:10.1016/j.cmet.2010.04.004

Connerth M, Tatsuta T, Haag M, Klecker T, Westermann B, Langer T. 2012. Intramitochondrial transport of phosphatidic acid in yeast by a lipid transfer protein. Science 338: 815-818. doi:10.1126/science. 1225625

Cunningham CN, Baughman JM, Phu L, Tea JS, Yu C, Coons M, Kirkpatrick DS, Bingol B, Corn JE. 2015. USP30 and parkin homeostatically regulate atypical ubiquitin chains on mitochondria. Nat Cell Biol 17: 160-169. doi:10.1038/ncb3097
Daumke O, Roux A. 2017. Mitochondrial homeostasis: How do dimers of mitofusins mediate mitochondrial fusion? Curr Biol 27: R353-R356. doi:10.1016/j.cub.2017.03.024

Del Dotto V, Mishra P, Vidoni S, Fogazza M, Maresca A, Caporali L, McCaffery JM, Cappelletti M, Baruffini E, Lenaers $\mathrm{G}$, et al. 2017. OPA1 isoforms in the hierarchical organization of mitochondrial functions. Cell Rep 19: 2557-2571. doi:10.1016/j.celrep.2017.05.073

Delettre C, Lenaers G, Griffoin JM, Gigarel N, Lorenzo C, Belenguer P, Pelloquin L, Grosgeorge J, Turc-Carel C, Perret E, et al. 2000. Nuclear gene OPA1, encoding a mitochondrial dynamin-related protein, is mutated in dominant optic atrophy. Nat Genet 26: 207-210. doi: $10.1038 / 79936$

Di Bella D, Lazzaro F, Brusco A, Plumari M, Battaglia G, Pastore A, Finardi A, Cagnoli C, Tempia F, Frontali M, et al. 2010. Mutations in the mitochondrial protease gene AFG3L2 cause dominant hereditary ataxia SCA28. Nat Genet 42: 313-321. doi:10.1038/ng.544

Dogan SA, Pujol C, Maiti P, Kukat A, Wang S, Hermans S, Senft K, Wibom R, Rugarli EI, Trifunovic A. 2014. Tissuespecific loss of DARS2 activates stress responses independently of respiratory chain deficiency in the heart. Cell Metab 19: 458-469. doi:10.1016/j.cmet.2014.02.004

Domenech E, Maestre C, Esteban-Martinez L, Partida D, Pascual R, Fernandez-Miranda G, Seco E, Campos-Olivas R, Perez M, Megias D, et al. 2015. AMPK and PFKFB3 mediate glycolysis and survival in response to mitophagy during mitotic arrest. Nat Cell Biol 17: 1304-1316. doi:10.1038/ncb3231

Durcan TM, Fon EA. 2015. The three 'P's of mitophagy: PARKIN, PINK1, and post-translational modifications. Genes Dev 29: 989-999. doi:10.1101/gad.262758.115

Ekstrand MI, Falkenberg M, Rantanen A, Park CB, Gaspari M, Hultenby K, Rustin P, Gustafsson CM, Larsson NG. 2004. Mitochondrial transcription factor A regulates mtDNA copy number in mammals. Hum Mol Genet 13: $935-944$. doi:10.1093/hmg/ddh109

Eldomery MK, Akdemir ZC, Vogtle FN, Charng WL, Mulica P, Rosenfeld JA, Gambin T, Gu S, Burrage LC, Al Shamsi A, et al. 2016. MIPEP recessive variants cause a syndrome of left ventricular non-compaction, hypotonia, and infantile death. Genome Med 8: 106. doi:10.1186/s13073-0160360-6

Esteban-Martinez L, Sierra-Filardi E, McGreal RS, SalazarRoa M, Marino G, Seco E, Durand S, Enot D, Grana O, Malumbres M, et al. 2017. Programmed mitophagy is essential for the glycolytic switch during cell differentiation. $E M B O J$ 36: 1688-1706. doi:10.15252/embj. 201695916

Faccenda D, Nakamura J, Gorini G, Dhoot GK, Piacentini M, Yoshida M, Campanella M. 2017. Control of mitochondrial remodeling by the ATPase inhibitory factor 1 unveils a pro-survival relay via OPA1. Cell Rep 18: 18691883. doi:10.1016/j.celrep.2017.01.070

Falkevall A, Alikhani N, Bhushan S, Pavlov PF, Busch K, Johnson KA, Eneqvist T, Tjernberg L, Ankarcrona M, Glaser E. 2006. Degradation of the amyloid $\beta$-protein by the novel mitochondrial peptidasome, PreP. J Biol Chem 281: 29096-29104. doi:10.1074/jbc.M602532200

Fischer F, Langer JD, Osiewacz HD. 2016. Identification of potential mitochondrial CLPXP protease interactors and 
substrates suggests its central role in energy metabolism. Sci Rep 5: 18375. doi:10.1038/srep18375

Flynn JM, Neher SB, Kim YI, Sauer RT, Baker TA. 2003. Proteomic discovery of cellular substrates of the ClpXP protease reveals five classes of ClpX-recognition signals. Mol Cell 11: 671-683. doi:10.1016/S1097-2765(03) 00060-1

Fu J, Yu HM, Chiu SY, Mirando AJ, Maruyama EO, Cheng JG, Hsu W. 2014. Disruption of SUMO-specific protease 2 induces mitochondria mediated neurodegeneration. PLoS Genet 10: e1004579. doi:10.1371/journal. pgen.1004579

Fukuda R, Zhang H, Kim JW, Shimoda L, Dang CV, Semenza GL. 2007. HIF-1 regulates cytochrome oxidase subunits to optimize efficiency of respiration in hypoxic cells. Cell 129: 111-122. doi:10.1016/j.cell.2007.01.047

Gakh O, Cavadini P, Isaya G. 2002. Mitochondrial processing peptidases. Biochim Biophys Acta 1592: 63-77. doi:10.1016/S0167-4889(02)00265-3

Gispert S, Parganlija D, Klinkenberg M, Drose S, Wittig I, Mittelbronn M, Grzmil P, Koob S, Hamann A, Walter M, et al. 2013. Loss of mitochondrial peptidase Clpp leads to infertility, hearing loss plus growth retardation via accumulation of CLPX, mtDNA and inflammatory factors. Hum Mol Genet 22: 4871-4887. doi:10.1093/hmg/ddt338

Gomes LC, Di Benedetto G, Scorrano L. 2011. During autophagy mitochondria elongate, are spared from degradation and sustain cell viability. Nat Cell Biol 13:589-598. doi: $10.1038 /$ ncb2220

Granot Z, Kobiler O, Melamed-Book N, Eimerl S, Bahat A, Lu B, Braun S, Maurizi MR, Suzuki CK, Oppenheim AB, et al. 2007. Turnover of mitochondrial steroidogenic acute regulatory (StAR) protein by Lon protease: The unexpected effect of proteasome inhibitors. Mol Endocrinol 21: 2164-2177. doi:10.1210/me.2005-0458

Greene AW, Grenier K, Aguileta MA, Muise S, Farazifard R, Haque ME, McBride HM, Park DS, Fon EA. 2012. Mitochondrial processing peptidase regulates PINK1 processing, import and Parkin recruitment. EMBO Rep 13: 378-385. doi:10.1038/embor.2012.14

Guo C, Hildick KL, Luo J, Dearden L, Wilkinson KA, Henley JM. 2013. SENP3-mediated deSUMOylation of dynaminrelated protein 1 promotes cell death following ischaemia. EMBO J 32: 1514-1528. doi:10.1038/emboj.2013.65

Guo C, Wilkinson KA, Evans AJ, Rubin PP, Henley JM. 2017. SENP3-mediated deSUMOylation of Drp1 facilitates interaction with Mff to promote cell death. Sci Rep 7: 43811. doi:10.1038/srep43811

Hartmann B, Wai T, Hu H, MacVicar T, Musante L, FischerZirnsak B, Stenzel W, Graf R, van den Heuvel L, Ropers $\mathrm{HH}$, et al. 2016. Homozygous YME1L1 mutation causes mitochondriopathy with optic atrophy and mitochondrial network fragmentation. eLife 5: e16078. doi: 10.7554/ eLife. 16078

Haynes CM, Petrova K, Benedetti C, Yang Y, Ron D. 2007. $\mathrm{ClpP}$ mediates activation of a mitochondrial unfolded protein response in C. elegans. Dev Cell 13: 467-480. doi:10.1016/j.devcel.2007.07.016

Herlan M, Vogel F, Bornhövd C, Neupert W, Reichert AS 2003. Processing of Mgm1 by the rhomboid-type protease Pcp1 is required for maintenance of mitochondrial morphology and of mitochondrial DNA. J Biol Chem 278: 27781-27788. doi:10.1074/jbc.M211311200

Herlan M, Bornhövd C, Hell K, Neupert W, Reichert AS. 2004. Alternative topogenesis of Mgm1 and mitochondrial morphology depend on ATP and a functional import motor. J Cell Biol 165: 167-173. doi:10.1083/ jcb.200403022

Hornig-Do HT, Tatsuta T, Buckermann A, Bust M, Kollberg G, Rötig A, Hellmich M, Nijtmans L, Wiesner RJ. 2012. Nonsense mutations in the COX1 subunit impair the stability of respiratory chain complexes rather than their assembly. EMBO J 31: 1293-1307. doi:10.1038/emboj. 2011.477

Horvath SE, Daum G. 2013. Lipids of mitochondria. Prog Lipid Res 52: 590-614. doi:10.1016/j.plipres.2013.07.002

Horvath SE, Bottinger L, Vogtle FN, Wiedemann N, Meisinger C, Becker T, Daum G. 2012. Processing and topology of the yeast mitochondrial phosphatidylserine decarboxylase 1. J Biol Chem 287: 36744-36755. doi: 10.1074/jbc.M112.398107

Hu J, Bianchi F, Ferguson M, Cesario A, Margaritora S, Granone P, Goldstraw P, Tetlow M, Ratcliffe C, Nicholson AG, et al. 2005. Gene expression signature for angiogenic and nonangiogenic non-small-cell lung cancer. Oncogene 24: 1212-1219. doi:10.1038/sj.onc. 1208242

Ieva R, Heisswolf AK, Gebert M, Vogtle FN, Wollweber F, Mehnert CS, Oeljeklaus S, Warscheid B, Meisinger C, van der Laan M, et al. 2013. Mitochondrial inner membrane protease promotes assembly of presequence translocase by removing a carboxy-terminal targeting sequence. Nat Commun 4: 2853. doi:10.1038/ncomms3853

Ishihara N, Fujita Y, Oka T, Mihara K. 2006. Regulation of mitochondrial morphology through proteolytic cleavage of OPA1. EMBO J 25: 2966-2977. doi:10.1038/sj.emboj.7601184

Jiang X, Jiang H, Shen Z, Wang X. 2014. Activation of mitochondrial protease OMA1 by Bax and Bak promotes cytochrome c release during apoptosis. Proc Natl Acad Sci 111: 14782-14787. doi:10.1073/pnas.1417253111

Jin SM, Lazarou M, Wang C, Kane LA, Narendra DP, Youle RJ. 2010. Mitochondrial membrane potential regulates PINK1 import and proteolytic destabilization by PARL J Cell Biol 191: 933-942. doi:10.1083/jcb.201008084

Jobling RK, Assoum M, Gakh O, Blaser S, Raiman JA, Mignot C, Roze E, Durr A, Brice A, Levy N, et al. 2015. PMPCA mutations cause abnormal mitochondrial protein processing in patients with non-progressive cerebellar ataxia. Brain 138: 1505-1517. doi:10.1093/brain/ awv057

Joshi M, Anselm I, Shi J, Bale TA, Towne M, Schmitz-Abe K, Crowley L, Giani FC, Kazerounian S, Markianos K, et al. 2016. Mutations in the substrate binding glycine-rich loop of the mitochondrial processing peptidase- $\alpha$ protein (PMPCA) cause a severe mitochondrial disease. Cold Spring Harb Mol Case Stud 2: a000786. doi:10.1101/ mcs.a000786

Kambacheld M, Augustin S, Tatsuta T, Müller S, Langer T. 2005. Role of the novel metallopeptidase Mop112 and saccharolysin for the complete degradation of proteins residing in different subcompartments of mitochondria. J Biol Chem 280: 20132-20139. doi:10.1074/jbc.M500 398200 
S. Ahola et al.

Kang SG, Ortega J, Singh SK, Wang N, Huang NN, Steven AC, Maurizi MR. 2002. Functional proteolytic complexes of the human mitochondrial ATP-dependent protease, hClpXP. J Biol Chem 277: 21095-21102. doi:10.1074/ jbc.M201642200

Kardon JR, Yien YY, Huston NC, Branco DS, Hildick-Smith GJ, Rhee KY, Paw BH, Baker TA. 2015. Mitochondrial ClpX activates a key enzyme for heme biosynthesis and erythropoiesis. Cell 161: 858-867. doi:10.1016/j.cell. 2015.04.017

Kaufman BA, Durisic N, Mativetsky JM, Costantino S, Hancock MA, Grutter P, Shoubridge EA. 2007. The mitochondrial transcription factor TFAM coordinates the assembly of multiple DNA molecules into nucleoid-like structures. Mol Biol Cell 18: 3225-3236. doi:10.1091/ mbc.e07-05-0404

Keckesova Z, Donaher JL, De Cock J, Freinkman E, Lingrell S, Bachovchin DA, Bierie B, Tischler V, Noske A, Okondo $M C$, et al. 2017. LACTB is a tumour suppressor that modulates lipid metabolism and cell state. Nature 543: 681686. doi:10.1038/nature21408

Khalimonchuk O, Jeong MY, Watts T, Ferris E, Winge DR. 2012. Selective Omal protease-mediated proteolysis of Coxl subunit of cytochrome oxidase in assembly mutants. J Biol Chem 287: 7289-7300. doi:10.1074/jbc M111.313148

Konig T, Troder SE, Bakka K, Korwitz A, Richter-Dennerlein R, Lampe PA, Patron M, Muhlmeister M, GuerreroCastillo S, Brandt U, et al. 2016. The m-AAA protease associated with neurodegeneration limits MCU activity in mitochondria. Mol Cell 64: 148-162. doi:10.1016/j. molcel.2016.08.020

Korwitz A, Merkwirth C, Richter-Dennerlein R, Troder SE, Sprenger HG, Quiros PM, Lopez-Otin C, Rugarli EI, Langer T. 2016. Loss of OMA1 delays neurodegeneration by preventing stress-induced OPA1 processing in mitochondria. J Cell Biol 212: 157-166. doi:10.1083/jcb. 201507022

Kraus F, Ryan MT. 2017. The constriction and scission machineries involved in mitochondrial fission. J Cell Sci 130: 2953-2960. doi:10.1242/jcs.199562

Kubota Y, Nomura K, Katoh Y, Yamashita R, Kaneko K, Furuyama K. 2016. Novel mechanisms for heme-dependent degradation of ALAS1 protein as a component of negative feedback regulation of heme biosynthesis. J Biol Chem 291: 20516-20529. doi:10.1074/jbc.M116.719161

Kunova N, Ondrovicova G, Bauer JA, Bellova J, Ambro L, Martinakova L, Kotrasova V, Kutejova E, Pevala V. 2017. The role of Lon-mediated proteolysis in the dynamics of mitochondrial nucleic acid-protein complexes. Sci Rep 7: 631. doi:10.1038/s41598-017-00632-8

Larsson NG, Wang J, Wilhelmsson H, Oldfors A, Rustin P, Lewandoski M, Barsh GS, Clayton DA. 1998. Mitochondrial transcription factor $A$ is necessary for mtDNA maintenance and embryogenesis in mice. Nat Genet 18: 231-236. doi:10.1038/ng0398-231

Lebeau J, Saunders JM, Moraes VWR, Madhavan A, Madrazo N, Anthony MC, Wiseman RL. 2018. The PERK arm of the unfolded protein response regulates mitochondrial morphology during acute endoplasmic reticulum stress. Cell Rep 22: 2827-2836. doi:10.1016/j.celrep. 2018.02.055
Lee JE, Westrate LM, Wu H, Page C, Voeltz GK. 2016. Multiple dynamin family members collaborate to drive mitochondrial division. Nature 540: 139-143. doi:10.1038/ nature20555

Lee H, Smith SB, Yoon Y. 2017. The short variant of the mitochondrial dynamin OPA1 maintains mitochondrial energetics and cristae structure. J Biol Chem 292: 71157130. doi:10.1074/jbc.M116.762567

Leonhard K, Guiard B, Pellecchia G, Tzagoloff A, Neupert W, Langer T. 2000. Membrane protein degradation by AAA proteases in mitochondria: Extraction of substrates from either membrane surface. Mol Cell 5: 629-638. doi:10.1016/S1097-2765(00)80242-7

Lu B, Lee J, Nie X, Li M, Morozov YI, Venkatesh S, Bogenhagen DF, Temiakov D, Suzuki CK. 2013. Phosphorylation of human TFAM in mitochondria impairs DNA binding and promotes degradation by the $\mathrm{AAA}^{+}$Lon protease. Mol Cell 49: 121-132. doi:10.1016/j.molcel. 2012.10.023

MacVicar T, Langer T. 2016. OPA1 processing in cell death and disease-The long and short of it. J Cell Sci 129: 2297-2306. doi:10.1242/jcs.159186

Maltecca F, Aghaie A, Schroeder DG, Cassina L, Taylor BA, Phillips SJ, Malaguti M, Previtali S, Guenet JL, Quattrini A, et al. 2008. The mitochondrial protease AFG3L2 is essential for axonal development. J Neurosci 28: $2827-$ 2836. doi:10.1523/jneurosci.4677-07.2008

Maltecca F, Magnoni R, Cerri F, Cox GA, Quattrini A, Casari G. 2009. Haploinsufficiency of $A F G 3 L 2$, the gene responsible for spinocerebellar ataxia type 28 , causes mitochondria-mediated Purkinje cell dark degeneration. J Neurosci 29: 9244-9254. doi:10.1523/jneurosci.1532-09.2009

Marcassa E, Kallinos A, Jardine J, Rusilowicz-Jones EV, Martinez A, Kuehl S, Islinger M, Clague MJ, Urbé S. 2018. Dual role of USP30 in controlling basal pexophagy and mitophagy. EMBO Rep 19: e45595. doi:10.15252/ embr.201745595

Martin LA, Kennedy BE, Karten B. 2016. Mitochondrial cholesterol: Mechanisms of import and effects on mitochondrial function. J Bioenerg Biomembr 48: 137-151. doi:10.1007/s10863-014-9592-6

Matsushima Y, Goto Y, Kaguni LS. 2010. Mitochondrial Lon protease regulates mitochondrial DNA copy number and transcription by selective degradation of mitochondrial transcription factor A (TFAM). Proc Natl Acad Sci 107: 18410-18415. doi:10.1073/pnas.1008924107

Matsushima Y, Hirofuji Y, Aihara M, Yue S, Uchiumi T, Kaguni LS, Kang D. 2017. Drosophila protease ClpXP specifically degrades DmLRPPRC1 controlling mitochondrial mRNA and translation. Sci Rep 7: 8315. doi:10.1038/s41598-017-08088-6

Meissner C, Lorenz H, Weihofen A, Selkoe DJ, Lemberg MK. 2011. The mitochondrial intramembrane protease PARL cleaves human Pink1 to regulate Pink1 trafficking. J Neurochem 117: 856-867. doi:10.1111/j.1471-4159. 2011.07253.x

Michel S, Wanet A, De Pauw A, Rommelaere G, Arnould T, Renard P. 2012. Crosstalk between mitochondrial (dys) function and mitochondrial abundance. J Cell Physiol 227: 2297-2310. doi:10.1002/jcp.23021 
Mishra P, Chan DC. 2016. Metabolic regulation of mitochondrial dynamics. J Cell Biol 212: 379-387. doi:10.1083/jcb.201511036

Mishra P, Carelli V, Manfredi G, Chan DC. 2014. Proteolytic cleavage of Opal stimulates mitochondrial inner membrane fusion and couples fusion to oxidative phosphorylation. Cell Metab 19: 630-641. doi:10.1016/j.cmet. 2014.03.011

Miyata N, Watanabe Y, Tamura Y, Endo T, Kuge O. 2016. Phosphatidylserine transport by Ups2-Mdm35 in respiration-active mitochondria. J Cell Biol 214: 77-88. doi:10.1083/jcb.201601082

Morino H, Pierce SB, Matsuda Y, Walsh T, Ohsawa R, Newby M, Hiraki-Kamon K, Kuramochi M, Lee MK, Klevit RE, et al. 2014. Mutations in Twinkle primase-helicase cause Perrault syndrome with neurologic features. Neurology 83: 2054-2061. doi:10.1212/WNL.0000000 000001036

Mossmann D, Meisinger C, Vögtle FN. 2012. Processing of mitochondrial presequences. Biochim Biophys Acta 1819: 1098-1106. doi:10.1016/j.bbagrm.2011.11.007

Mossmann D, Vogtle FN, Taskin AA, Teixeira PF, Ring J, Burkhart JM, Burger N, Pinho CM, Tadic J, Loreth D, et al. 2014. Amyloid- $\beta$ peptide induces mitochondrial dysfunction by inhibition of preprotein maturation. Cell Metab 20: 662-669. doi:10.1016/j.cmet.2014.07.024

Murakawa T, Yamaguchi O, Hashimoto A, Hikoso S, Takeda T, Oka T, Yasui H, Ueda H, Akazawa Y, Nakayama H, et al. 2015. Bcl-2-like protein 13 is a mammalian Atg32 homologue that mediates mitophagy and mitochondrial fragmentation. Nat Commun 6: 7527. doi:10.1038/ ncomms 8527

Nakamura N, Hirose S. 2008. Regulation of mitochondrial morphology by USP30, a deubiquitinating enzyme present in the mitochondrial outer membrane. $\mathrm{Mol} \mathrm{Biol} \mathrm{Cell}$ 19: 1903-1911. doi:10.1091/mbc.e07-11-1103

Nolden M, Ehses S, Koppen M, Bernacchia A, Rugarli EI, Langer T. 2005. The $m$-AAA protease defective in hereditary spastic paraplegia controls ribosome assembly in mitochondria. Cell 123: 277-289. doi:10.1016/j. cell.2005.08.003

Olichon A, Guillou E, Delettre C, Landes T, Arnaune-Pelloquin L, Emorine LJ, Mils V, Daloyau M, Hamel C, AmatiBonneau P, et al. 2006. Mitochondrial dynamics and disease, OPA1. Biochim Biophys Acta 1763: 500-509. doi:10.1016/j.bbamcr.2006.04.003

Osman C, Wilmes C, Tatsuta T, Langer T. 2007. Prohibitins interact genetically with Atp23, a novel processing peptidase and chaperone for the $\mathrm{F}_{1} \mathrm{~F}_{0}$-ATP synthase. Mol Biol Cell 18: 627-635. doi:10.1091/mbc.e06-09-0839

Patron M, Sprenger HG, Langer T. 2018. m-AAA proteases, mitochondrial calcium homeostasis and neurodegeneration. Cell Res 28: 296-306. doi:10.1038/cr.2018.17

Perrault M, Klotz B, Housset E. 1951. Two cases of Turner syndrome with deaf-mutism in two sisters. Bull Mem Soc Med Hop Paris 67: 79-84.

Petek E, Windpassinger C, Vincent JB, Cheung J, Boright AP, Scherer SW, Kroisel PM, Wagner K. 2001. Disruption of a novel gene (IMMP2L) by a breakpoint in $7 \mathrm{q} 31$ associated with Tourette syndrome. Am J Hum Genet 68: 848858. doi:10.1086/319523
Pickrell AM, Youle RJ. 2015. The roles of PINK1, Parkin, and mitochondrial fidelity in Parkinson's disease. Neuron 85: 257-273. doi:10.1016/j.neuron.2014.12.007

Pierce SB, Chisholm KM, Lynch ED, Lee MK, Walsh T, Opitz JM, Li W, Klevit RE, King MC. 2011. Mutations in mitochondrial histidyl tRNA synthetase HARS2 cause ovarian dysgenesis and sensorineural hearing loss of Perrault syndrome. Proc Natl Acad Sci 108: 6543-6548. doi:10.1073/pnas.1103471108

Pierce SB, Gersak K, Michaelson-Cohen R, Walsh T, Lee MK, Malach D, Klevit RE, King MC, Levy-Lahad E. 2013. Mutations in LARS2, encoding mitochondrial leucyl-tRNA synthetase, lead to premature ovarian failure and hearing loss in Perrault syndrome. Am J Hum Genet 92: 614-620. doi:10.1016/j.ajhg.2013.03.007

Pinti M, Gibellini L, Liu Y, Xu S, Lu B, Cossarizza A. 2015. Mitochondrial Lon protease at the crossroads of oxidative stress, ageing and cancer. Cell Mol Life Sci 72: 4807-4824. doi:10.1007/s00018-015-2039-3

Potting C, Wilmes C, Engmann T, Osman C, Langer T. 2010. Regulation of mitochondrial phospholipids by Ups1/PRELI-like proteins depends on proteolysis and Mdm35. EMBO J 29: 2888-2898. doi:10.1038/emboj. 2010.169

Pryde KR, Taanman JW, Schapira AH. 2016. A LON-ClpP proteolytic axis degrades complex I to extinguish ROS production in depolarized mitochondria. Cell Rep 17: 2522-2531. doi:10.1016/j.celrep.2016.11.027

Quiros PM, Ramsay AJ, Sala D, Fernandez-Vizarra E, Rodriguez F, Peinado JR, Fernandez-Garcia MS, Vega JA, Enriquez JA, Zorzano A, et al. 2012. Loss of mitochondrial protease OMA1 alters processing of the GTPase OPA1 and causes obesity and defective thermogenesis in mice. $E M B O J$ 31: 2117-2133. doi:10.1038/emboj. 2012.70

Quiros PM, Espanol Y, Acin-Perez R, Rodriguez F, Barcena C, Watanabe K, Calvo E, Loureiro M, Fernandez-Garcia MS, Fueyo A, et al. 2014. ATP-dependent Lon protease controls tumor bioenergetics by reprogramming mitochondrial activity. Cell Rep 8: 542-556. doi:10.1016/j. celrep.2014.06.018

Quiros PM, Langer T, Lopez-Otin C. 2015. New roles for mitochondrial proteases in health, ageing and disease. Nat Rev Mol Cell Biol 16: 345-359. doi:10.1038/nrm3984

Rainbolt TK, Atanassova N, Genereux JC, Wiseman RL. 2013. Stress-regulated translational attenuation adapts mitochondrial protein import through Tim17A degradation. Cell Metab 18: 908-919. doi:10.1016/j.cmet. 2013.11.006

Rainbolt TK, Lebeau J, Puchades C, Wiseman RL. 2016. Reciprocal degradation of YME1L and OMA1 adapts mitochondrial proteolytic activity during stress. Cell Rep 14: 2041-2049. doi:10.1016/j.celrep.2016.02.011

Rambold AS, Kostelecky B, Elia N, Lippincott-Schwartz J. 2011. Tubular network formation protects mitochondria from autophagosomal degradation during nutrient starvation. Proc Natl Acad Sci 108: 10190-10195. doi:10.1073/pnas.1107402108

Rampello AJ, Glynn SE. 2017. Identification of a degradation signal sequence within substrates of the mitochondrial i-AAA protease. J Mol Biol 429: 873-885. doi:10.1016/j. jmb.2017.02.009 
S. Ahola et al.

Richter U, Lahtinen T, Marttinen P, Suomi F, Battersby BJ 2015. Quality control of mitochondrial protein synthesis is required for membrane integrity and cell fitness. $J$ Cell Biol 211: 373-389. doi:10.1083/jcb.201504062

Richter-Dennerlein R, Korwitz A, Haag M, Tatsuta T, Dargazanli S, Baker M, Decker T, Lamkemeyer T, Rugarli EI, Langer T. 2014. DNAJC19, a mitochondrial cochaperone associated with cardiomyopathy, forms a complex with prohibitins to regulate cardiolipin remodeling. Cell Metab 20: 158-171. doi:10.1016/j.cmet.2014.04.016

Rodger CE, McWilliams TG, Ganley IG. 2018. Mammalian mitophagy - From in vitro molecules to in vivo models. FEBS J 285: 1185-1202. doi: $10.1111 /$ febs. 14336

Saita S, Nolte H, Fiedler KU, Kashkar H, Venne AS, Zahedi RP, Krüger M, Langer T. 2017. PARL mediates Smac proteolytic maturation in mitochondria to promote apoptosis. Nat Cell Biol 19: 318-328. doi:10.1038/ncb3488

Saita S, Tatsuta T, Lampe PA, König T, Ohba Y, Langer T. 2018. PARL partitions the lipid transfer protein STARD7 between the cytosol and mitochondria. EMBO J 37: e97909. doi:10.15252/embj.201797909

Schmitt K, Grimm A, Dallmann R, Oettinghaus B, Restelli LM, Witzig M, Ishihara N, Mihara K, Ripperger JA, Albrecht U, et al. 2018. Circadian control of DRP1 activity regulates mitochondrial dynamics and bioenergetics. Cell Metab 27: 657-666.e5. doi:10.1016/j.cmet.2018.01.011

Seiferling D, Szczepanowska K, Becker C, Senft K, Hermans S, Maiti P, Konig T, Kukat A, Trifunovic A. 2016. Loss of CLPP alleviates mitochondrial cardiomyopathy without affecting the mammalian UPR ${ }^{\mathrm{mt}}$. EMBO Rep 17: 953964. doi:10.15252/embr.201642077

Sekine S, Kanamaru Y, Koike M, Nishihara A, Okada M, Kinoshita H, Kamiyama M, Maruyama J, Uchiyama Y, Ishihara N, et al. 2012. Rhomboid protease PARL mediates the mitochondrial membrane potential loss-induced cleavage of PGAM5. J Biol Chem 287: 34635-34645. doi:10.1074/jbc.M112.357509

Sepuri NBV, Angireddy R, Srinivasan S, Guha M, Spear J, Lu B, Anandatheerthavarada HK, Suzuki CK, Avadhani NG. 2017. Mitochondrial LON protease-dependent degradation of cytochrome $c$ oxidase subunits under hypoxia and myocardial ischemia. Biochim Biophys Acta 1858: 519528. doi:10.1016/j.bbabio.2017.04.003

Shi G, McQuibban GA. 2017. The mitochondrial rhomboid protease PARL is regulated by PDK2 to integrate mitochondrial quality control and metabolism. Cell Rep 18: 1458-1472. doi:10.1016/j.celrep.2017.01.029

Shi Y, Dierckx A, Wanrooij PH, Wanrooij S, Larsson NG, Wilhelmsson LM, Falkenberg M, Gustafsson CM. 2012. Mammalian transcription factor A is a core component of the mitochondrial transcription machinery. Proc Natl Acad Sci 109: 16510-16515. doi:10.1073/ pnas.1119738109

Sík A, Passer BJ, Koonin EV, Pellegrini L. 2004. Self-regulated cleavage of the mitochondrial intramembrane cleaving protease PARL yields $\mathrm{P} \beta$, a nuclear-targeted peptide. J Biol Chem 279: 15323-15329. doi:10.1074/jbc. M313756200

Silic-Benussi M, Scattolin G, Cavallari I, Minuzzo S, Del Bianco P, Francescato S, Basso G, Indraccolo S, D'Agostino DM, Ciminale V. 2018. Selective killing of human TALL cells: An integrated approach targeting redox ho- meostasis and the OMA1/OPA1 axis. Cell Death Dis 9: 822. doi:10.1038/s41419-018-0870-9

Stahl A, Moberg P, Ytterberg J, Panfilov O, Brockenhuus Von Lowenhielm H, Nilsson F, Glaser E. 2002. Isolation and identification of a novel mitochondrial metalloprotease (PreP) that degrades targeting presequences in plants. J Biol Chem 277: 41931-41939. doi:10.1074/jbc. M205500200

Stiburek L, Cesnekova J, Kostkova O, Fornuskova D, Vinsova K, Wenchich L, Houstek J, Zeman J. 2012. YME1L controls the accumulation of respiratory chain subunits and is required for apoptotic resistance, cristae morphogenesis, and cell proliferation. Mol Biol Cell 23: 1010-1023. doi:10.1091/mbc.e11-08-0674

Szczepanowska K, Maiti P, Kukat A, Hofsetz E, Nolte H, Senft K, Becker C, Ruzzenente B, Hornig-Do HT, Wibom $\mathrm{R}$, et al. 2016. CLPP coordinates mitoribosomal assembly through the regulation of ERAL1 levels. EMBO J 35: 2566-2583. doi:10.15252/embj.201694253

Taskin AA, Kucukkose C, Burger N, Mossmann D, Meisinger C, Vogtle FN. 2017. The novel mitochondrial matrix protease Ste23 is required for efficient presequence degradation and processing. Mol Biol Cell 28: 997-1002. doi:10.1091/mbc.e16-10-0732

Tatsuta T, Langer T. 2017. Intramitochondrial phospholipid trafficking. Biochim Biophys Acta 1862: 81-89. doi:10.1016/j.bbalip.2016.08.006

Varanita T, Soriano ME, Romanello V, Zaglia T, QuintanaCabrera R, Semenzato M, Menabo R, Costa V, Civiletto G, Pesce P, et al. 2015. The OPA1-dependent mitochondrial cristae remodeling pathway controls atrophic, apoptotic, and ischemic tissue damage. Cell Metab 21: 834-844. doi:10.1016/j.cmet.2015.05.007

Vogtle FN, Brandl B, Larson A, Pendziwiat M, Friederich MW, White SM, Basinger A, Kucukkose C, Muhle H, Jahn JA, et al. 2018. Mutations in PMPCB encoding the catalytic subunit of the mitochondrial presequence protease cause neurodegeneration in early childhood Am J Hum Genet 102: 557-573. doi:10.1016/j.ajhg. 2018.02.014

Wai T, Langer T. 2016. Mitochondrial dynamics and metabolic regulation. Trends Endocrinol Metab 27: 105-117. doi:10.1016/j.tem.2015.12.001

Wai T, Garcia-Prieto J, Baker MJ, Merkwirth C, Benit P, Rustin P, Ruperez FJ, Barbas C, Ibanez B, Langer T. 2015. Imbalanced OPA1 processing and mitochondrial fragmentation cause heart failure in mice. Science 350: aad0116. doi: 10.1126/science.aad0116

Wai T, Saita S, Nolte H, Muller S, Konig T, Richter-Dennerlein R, Sprenger HG, Madrenas J, Muhlmeister M, Brandt U, et al. 2016. The membrane scaffold SLP2 anchors a proteolytic hub in mitochondria containing PARL and the $i$-AAA protease YME1L. EMBO Rep 17: 1844-1856. doi:10.15252/embr.201642698

Wang K, Jin M, Liu X, Klionsky DJ. 2013. Proteolytic processing of Atg32 by the mitochondrial $i$-AAA protease Yme1 regulates mitophagy. Autophagy 9: 1828-1836. doi:10.4161/auto.26281

Watanabe Y, Tamura Y, Kawano S, Endo T. 2015. Structural and mechanistic insights into phospholipid transfer by Ups1-Mdm35 in mitochondria. Nat Commun 6: 7922. doi:10.1038/ncomms8922 
Mitochondrial Proteolysis and Metabolic Control

Wu H, Xue D, Chen G, Han Z, Huang L, Zhu C, Wang X, Jin $\mathrm{H}$, Wang J, Zhu Y, et al. 2014. The BCL2L1 and PGAM5 axis defines hypoxia-induced receptor-mediated mitophagy. Autophagy 10: 1712-1725. doi:10.4161/auto.29568

Xiao X, Hu Y, Quiros PM, Wei Q, Lopez-Otin C, Dong Z. 2014. OMA1 mediates OPA1 proteolysis and mitochondrial fragmentation in experimental models of ischemic kidney injury. Am J Physiol Renal Physiol 306: F1318F1326. doi:10.1152/ajprenal.00036.2014

Yamano K, Youle RJ. 2013. PINK1 is degraded through the N-end rule pathway. Autophagy 9: 1758-1769. doi:10.4161/auto. 24633

Yien YY, Ducamp S, van der Vorm LN, Kardon JR, Manceau H, Kannengiesser C, Bergonia HA, Kafina MD, Karim Z, Gouya L, et al. 2017. Mutation in human CLPX elevates levels of $\delta$-aminolevulinate synthase and protopor- phyrin IX to promote erythropoietic protoporphyria Proc Natl Acad Sci 114: E8045-E8052. doi:10.1073/ pnas.1700632114

Youle RJ, van der Bliek AM. 2012. Mitochondrial fission, fusion, and stress. Science 337: 1062-1065. doi:10.1126 science. 1219855

Yue W, Chen Z, Liu H, Yan C, Chen M, Feng D, Yan C, Wu H, Du L, Wang Y, et al. 2014. A small natural molecule promotes mitochondrial fusion through inhibition of the deubiquitinase USP30. Cell Res 24: 482-496. doi:10.1038/ cr.2014.20

Zeng X, Neupert W, Tzagoloff A. 2007. The metalloprotease encoded by ATP23 has a dual function in processing and assembly of subunit 6 of mitochondrial ATPase. Mol Biol Cell 18: 617-626. doi:10.1091/mbc.e06-090801 


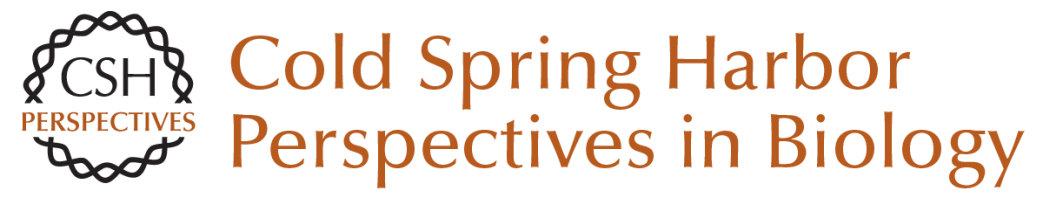

\section{Mitochondrial Proteolysis and Metabolic Control}

Sofia Ahola, Thomas Langer and Thomas MacVicar

Cold Spring Harb Perspect Biol 2019; doi: 10.1101/cshperspect.a033936 originally published online January 22, 2019

\section{Subject Collection Protein Homeostasis}

Proteome-Scale Mapping of Perturbed Proteostasis in Living Cells

Isabel Lam, Erinc Hallacli and Vikram Khurana

Pharmacologic Approaches for Adapting Proteostasis in the Secretory Pathway to Ameliorate Protein Conformational Diseases Jeffery W. Kelly

Cell-Nonautonomous Regulation of Proteostasis in Aging and Disease

Richard I. Morimoto

The Autophagy Lysosomal Pathway and

Neurodegeneration

Steven Finkbeiner

Functional Modules of the Proteostasis Network Gopal G. Jayaraj, Mark S. Hipp and F. Ulrich Hartl

Protein Solubility Predictions Using the CamSol Method in the Study of Protein Homeostasis Pietro Sormanni and Michele Vendruscolo

Recognition and Degradation of Mislocalized Proteins in Health and Disease

Ramanujan S. Hegde and Eszter Zavodszky

The Nuclear and DNA-Associated Molecular Chaperone Network

Zlata Gvozdenov, Janhavi Kolhe and Brian C. Freeman
The Amyloid Phenomenon and Its Significance in Biology and Medicine

Christopher M. Dobson, Tuomas P.J. Knowles and Michele Vendruscolo

A Chemical Biology Approach to the Chaperome

in Cancer--HSP90 and Beyond

Tony Taldone, Tai Wang, Anna Rodina, et al.

Proteostasis in Viral Infection: Unfolding the Complex Virus-Chaperone Interplay Ranen Aviner and Judith Frydman

The Proteasome and Its Network: Engineering for Adaptability Daniel Finley and Miguel A. Prado

Functional Amyloids Daniel Otzen and Roland Riek

Chaperone Interactions at the Ribosome Elke Deuerling, Martin Gamerdinger and Stefan G. Kreft

Mechanisms of Small Heat Shock Proteins Maria K. Janowska, Hannah E.R. Baughman, Christopher N. Woods, et al.

Structure, Function, and Regulation of the Hsp90 Machinery

Maximilian M. Biebl and Johannes Buchner

For additional articles in this collection, see http://cshperspectives.cshlp.org/cgi/collection/

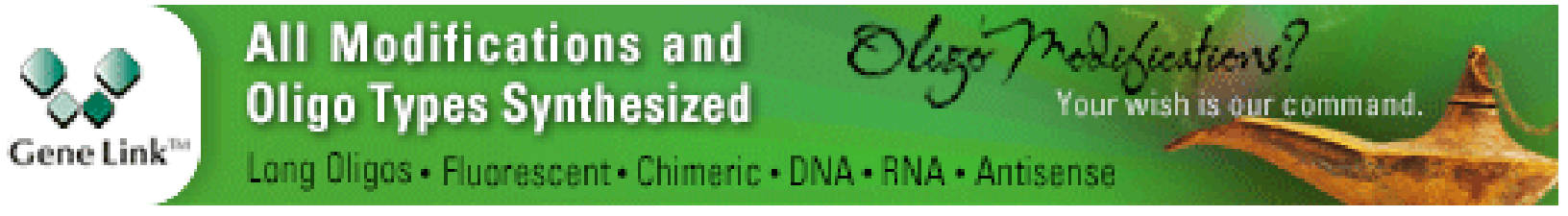


For additional articles in this collection, see http://cshperspectives.cshlp.org/cgi/collection/

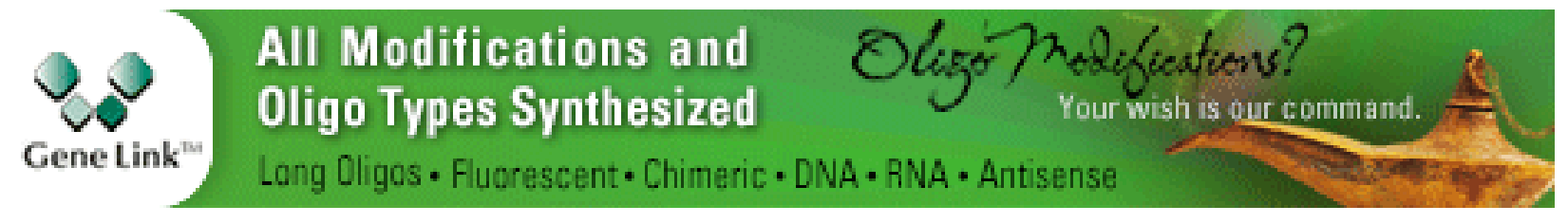

Copyright @ 2019 Cold Spring Harbor Laboratory Press; all rights reserved 